\title{
Fluid Bed Film Coating of Fine Ibuprofen Particles
}

4

Otto H. York Department of Chemical, Biological and Pharmaceutical Engineering, New Jersey Institute of Technology, Newark, New Jersey, USA 


\section{Abstract}

Fine pharmaceutical powders pose significant challenge in fluid bed (FB) film coating due to their high cohesion. Ibuprofen powders, considered as model Geldart group C powders with Sauter mean diameters of $41 \mu \mathrm{m}$ (coarse) and $22 \mu \mathrm{m}$ (micronized), could not be fluidized due to severe agglomeration, solid-bridging, and poor flowability. Dry coating, applied as a pre-processing method that coats nano-silica on the surface of ibuprofen, enabled sufficiently improved flow, hence fluidization via reduced cohesion. Resulting coarse and micronized ibuprofen powders were successfully polymer film coated in a top spray fluidized bed. As a major novelty, apart from pre-processing through $20 \mathrm{~nm}$ silica surface coating that enabled fluidization, agglomeration during FB processing was minimized by introducing $180 \mathrm{~nm}$ colloidal silica particles that were $\mathrm{pH}$ stabilized in polymer spraying suspension using $\mathrm{NaOH}$. In contrast, lack of or poorly stabilized colloidal particles led to significant agglomeration. Spray rate and fluidization velocity were both investigated to understand their effect on agglomeration of the coarse ibuprofen powders. Increased spray rate led to increased agglomeration due to the overly wet conditions, while increased fluidization velocities unexpectedly led to increased agglomeration resulting from electrostatic charging. To simplify the experimental design, a simple scaling relationship was introduced to estimate the coating conditions for the micronized ibuprofen powders based on the processing conditions of the coarse ibuprofen powders. This relationship, based on the minimum fluidization velocity, led to comparable agglomeration levels for powders with Sauter mean diameters of 21 and $42 \mu \mathrm{m}$. To the author's knowledge these are the first successful results where micronized pharmaceutical powders were polymer coated in a traditional top spray fluidized bed.

Keywords: Fluidization of group C powders, dry coating, pharmaceutical powders, polymer film coating, reduced agglomeration 


\section{Introduction}

Fluidized bed techniques are commonly used for coating and agglomeration of active pharmaceutical ingredients (API) to enhance their powder flow and handling capabilities as well as to impart desirable characteristics associated with the coating material, such as modified release behavior, protection from the environment or to mask unpleasant tastes or odors [1-5]. Incorporating fine active particles into pharmaceutical products is highly desirable because of their high specific surface area, which can enhance the dissolution and therefore the bioavailability of most poorly water soluble materials [6]. Unfortunately, fluidized bed coating is typically limited to particle sizes appreciably greater than 100 microns without severe agglomeration [7]. These fine API particles can often be categorized as Group C (cohesive) by the Geldart classification system, which are extremely difficult to

47 formation of channels or ratholes. To overcome these processing issues, small particles are commonly granulated with much larger, easily fluidizing powders to enhance processing [9-12]. While such approaches are capable of producing well coated products, it has the disadvantages of limited potency ranges, due to the high concentration of the well fluidizing excipients and can be problematic for products requiring high drug loadings. Additionally, these granules are typically on the size of several 100s of microns which may have a larger size than is desirable or could lead to size segregation [13]. particles without the addition of significant amounts of excipient materials, however most of these

55 methods require complicated and potentially expensive modifications to the typical fluidized bed configuration. Kawaguchi et al. [14] showed that a rotating fluidizing bed configuration was capable of

57 fluidizing and granulating cohesive API particles to prepare reproducible acetaminophen granules ( $\sim 500$ $58 \mu \mathrm{m})$, which were difficult to produce in a conventional fluidized bed. Later Watano and collaborators 
showed that $15 \mu \mathrm{m}$ cornstarch particles could be granulated [15] or individually coated [16] in a rotating

60 fluidized bed. They explained that the centrifugal forces exerted onto the normally cohesive cornstarch

61 particle increased the apparent particle weight and made them behave like well fluidizing Geldart group

62 A (aeratable) particles. In another study, Hamashita et al. also showed that micronized core particles

63 containing ibuprofen could be granulated using an impeller agitated conventional fluidized bed [17-19].

64 A similar apparatus was used to produce micro-granules of ibuprofen particles by Miyadai et al. [20].

65 While these methods were capable of producing reproducible agglomerates with high loadings of active

66 materials, the resulting granules had median sizes larger than $200 \mu \mathrm{m}$. In addition, such processing

67 requires expensive and potentially complicated technologies that can be difficult to integrate into

68 pharmaceutical manufacturing.

Ichikawa and Fukumori showed in a series of studies that micronized and cohesive powders could be successfully coated and agglomerated in a bottom spray Wurster type spouted bed [13, 21, 22]. However, because of the cohesive nature of these micronized particles, they could not be fluidized in a

72 strict sense; hence, high superficial velocities were required to make them spout and a draft tube was 73 used to enhance the circulation. The authors, however, also cited problems maintaining a steady 74 circulation of these cohesive powders, due to their inability to be fluidized in a traditional sense, which 75 can make process development difficult. Therefore an easier and more effective method of fluidized bed 76 coating these fine cohesive powders needs to be established if it is to be widely used in industry. beds. However, analysis of the cohesive forces versus other forces such as buoyancy or resultant drag 79 forces indicate that in order to easily counteract cohesion, one may need to either increase the body weight of the powders, which was performed by Watano et al. $[15,16]$, or one can find ways to reduce 81 cohesion. In present work, latter is considered as a practical way to enhance fluidization of Group C 
82 powders. Although cohesion reduction via introducing flow additives to the fine powders has been

83 known for several decades, it could also be used to promote fluidization as was shown in US patent $846833185[23]$. However, surface modification through dry coating of nano-sized flow additives, which is a 85 simple and practical method, has been shown to provide more significant and reliable results as 86 compared to additive blending [24]. Consequently, it has been shown to make cohesive powders behave 87 like well flowing, thus potentially fluidizable [24]. In dry coating, a discrete, fairly uniform layer of nanosilica particles is applied onto the surface of the cohesive host particles. In contrast, the simple addition 89 of glidants through conventional blending methods could leave most of the additives in the form of agglomerates, which are incapable of significantly impacting the flow [24]. Several methods have been developed to achieve high quality surface coatings in a dry process [6, 23-29]. These methods have

92 been shown to offer substantial flow improvements by simultaneously deagglomerating the cohesive 93 nano-silica, i.e., glidant powders, and dispersing the nano-silica particles across the host or carrier 94 particle surface, which include Magnetically Assisted Impaction Coating [24, 30-34], Acoustic Mixing 95 [26], and Fluid Energy Milling [6, 27]. Yang et al. derived a simple equation that showed that the 96 reduction in cohesion due to the introduction of the nano-sized surface asperity in the form of the nano97 silica coating is inversely proportional to particle size [24], hence coating of nano-silica would lead to 98 improvements in the flow properties. Chen and collaborators [30-32] later showed that indeed the 99 surface asperities, the level of coating (expressed in terms of surface area coverage, SAC) as well as the 100 surface energy, play a major role in the cohesion reduction, and that the addition of a nano-silica surface 101 coating can reduce the granular bond number (the ratio of the cohesive forces to the inertial forces) by 102 over an order of magnitude for aluminum particles under $5 \mu \mathrm{m}$. In addition to flow improvement, this 103 cohesion reduction also allowed fine cohesive particles to be fluidized in a conventional fluidized bed $104[31,32]$ and led to fluidized bed coated product without significant agglomeration. While this is a 105 promising development, the type of particles considered were aluminum, having relatively high density 
and hence body weight, or cornstarch, which is highly spherical and had relatively narrow size

107 distribution. In contrast, drug particles typically have higher levels of cohesion, irregular shapes, and 108 wider size distributions. Recent work on dry coating drug powders indicate that their cohesion can be 109 reduced, albeit less significantly than materials like cornstarch, via dry coating of silica, however, their 110 fluidization behavior has not been investigated [35]. More importantly, film coating of such particles via 111 fluidized bed processing had not been investigated, including examination of conditions that allow for 112 maintaining fluidization during coating, while avoiding particle agglomeration. Thus the major objective 113 of this work is to examine fluidization and subsequent polymer film coating of very fine pharmaceutical 114 powders.

In this study silica nanoparticles were dry coated onto the surface of as received and micronized

116 ibuprofen particles with a median size in the range of 41 to $74 \mu \mathrm{m}$ and corresponding Sauter mean 117 diameter of 21 to $41 \mu \mathrm{m}$, respectively. Ibuprofen was selected as a model drug because of its poor 118 flowability and hence poor fluidizability. It will be shown that dry coating, while not strictly necessary for 119 fluidizing larger API particles, is necessary for fine micronized particles, which are Geldart group C 120 powders. It is shown that the dry coating of the nano-silica particles allows these previously cohesive 121 particles to be fluidized bed coated with minimal agglomeration. It will also be demonstrated that while 122 simple blending with nano-silica can improve the flow properties, it could not offer the same fluidization 123 enhancements as dry coating. To the author's knowledge, the work presented here represents the first 124 successful study of fluidized bed coating of fine, micronized ibuprofen particles in a top spray fluidized 125 bed, without the necessity of equipment modification or the presence of coarse excipient particles. 


\section{Experimental}

127 Materials

128

129

130

131

132

133

134

135

136

137

138

139

140

Ibuprofen, IBU50 $\left(d_{10}=24, d_{50}=70, d_{90}=160 \mu \mathrm{m}\right)$ and IBU90 $\left(d_{10}=21, d_{50}=113, d_{90}=295 \mu \mathrm{m}\right)$, was a generous gift from BASF (NJ, USA); nano-silica (Aerosil R972p, $d_{p}=16 \mathrm{~nm}$ ) and Eudragit RS100 were a generous gift from Evonik Degussa (NJ, USA); and HPMC (Methocel E15) was a generous gift from Dow Chemicals (Delaware, USA). ACS reagent grades of ethanol (EtOH), sodium hydroxide $(\mathrm{NaOH})$ and nitric acid (HNO3), tetraethyl orthosilicate (TEOS), ammonium hydroxide ( $\mathrm{NH} 4 \mathrm{OH}$ ) were purchased from Sigma-Aldrich and used without further purification.

\section{Methods}

\section{Preparation of $180 \mathrm{~nm}$ Silica Particles}

Colloidal silica particles were synthesized according to a process introduced by Stober et al. [36], which allows for fabricating mostly monodisperse spherical particles in sizes from tens to thousands of nanometers. Through this process, TEOS was hydrolyzed to form silica particles in ethanol with an $\mathrm{NH} 4 \mathrm{OH}$ catalyst. In each batch, TEOS, ethanol, $\mathrm{NH} 4 \mathrm{OH}$, and deionized water were mixed according to certain molar ratios and stirred for $2 \mathrm{~d}$ at room temperature.

\section{Preparation of Uncoated and Dry Coated Powders}

Uncoated, dry coated and v-blended powders produced in this study are summarized in Table 1, along with their sizes and the coating methods used. These powders were investigated to determine the preconditioning steps, namely, v-blending or dry coating, necessary to produce well flowing and fluidizable powders. Uncoated ibuprofen was produced by sieving as received IBU50 through a 60 mesh sieve $(250 \mu \mathrm{m})$ to break up and remove large chunks that formed during storage. V-blended powder was prepared by blending the sieved powder with 2 wt\% R972p in a V-shaped blender (Blend Master, 
Model B Lab Blender Pk \# Ib 11011, Patterson Kelly, Pa, USA), which was rotated at 27 RPM for 148 rotations.

Dry coated powder was prepared in a LabRAM acoustic mixer (Resodyne, MT, USA). As received IBU50, without sieving, was combined with $2 \mathrm{wt} \% \mathrm{R} 972 \mathrm{p}$ and charged into a $500 \mathrm{~mL}$ plastic jar with a total loading of $125 \mathrm{~g}$. The jar was secured into the LabRAM acoustic mixer and vibrated at $70-75 \mathrm{G}^{\prime} \mathrm{s}$ for 5 minutes at a frequency of about $60 \mathrm{~Hz}$. The resulting powder was ibuprofen dry coated with nanosilica. For more detailed descriptions of the LabRAM dry coating process, please refer to Mullarney et al. [26]

A similar procedure was used to produce fine coated and uncoated ibuprofen powders. Prior to the coating process as received IBU90 was milled in a Fluid Energy Mill (Qualification Micronizer, Sturtevant, WI, USA) to produce fine ibuprofen particles $\left(d_{10}=10, d_{50}=41, d_{90}=130 \mu \mathrm{m}\right)$. The ibuprofen was fed into the mill at $6 \mathrm{~g} / \mathrm{min}$ with a screw feeder (AccuRate volumentric feeder, Schneck, Whitewater, WI, USA ) and the mill was operated at a feed pressure and grinding pressure of 15 and 10 psi, respectively. The fine particles were collected from the collection jar. After micronizing, the milled version of the uncoated, V-blended and dry coated powders with $2 \%$ R972p nano-silica were prepared in the same way, as described above.

\section{Powder Flow and Fluidization Characterization}

Ibuprofen, before and after dry coating, was characterized to determine the effect of dry coating on the flow and fluidization behavior. The Hosakowa Powder Tester (Hosakowa, Japan) and the FT4 Powder Tester (Freeman Technologies Ltd, Worcestershire, UK) were used to characterize the flow and packing properties of the coated and uncoated powders. The Hosakowa Powder Tester was used to measure the angle of repose (AOR) as described by the ASTM standard ASTM D6393-08 [37]. The FT4 Powder Rheometer with shear cell module was used to measure the shear stress at $3 \mathrm{kPa}$ based on the 
171 recommendation of the ASTM standard for powders having low density [38] and the range normally

172 used for pharmaceutical powders. A Mohr diagram was constructed to determine the flow function

173 coefficient, FFC, which is an indication of how easily powder could flow once consolidated and is defined

174 by the ratio of maximum principle stress and the unconfined yield stress. Shulze has developed the

175 following FFC categories to describe powder flow: FFC $<1$, not flowing; $1<$ FFC $<2$, very cohesive; $2<$

$176 \mathrm{FFC}<4$, cohesive; $4<\mathrm{FFC}<10$, easy flowing, and FFC $>10$, free-flowing [39].

The fluidization behavior of the coated and uncoated powders was characterized with a conventional de-fluidization experiment and the FT4 Powder Tester's aeration test. In the aeration test, powder was placed in a $35 \mathrm{~mL}$ glass cylinder (25 mm diameter) with a stainless steel distributor plate. A rotating conditioning blade was passed through the powder bed with and without flowing dry compressed air at various superficial gas velocities in the range of $0-2.0 \mathrm{~cm} / \mathrm{s}$ at $0.2 \mathrm{~cm} / \mathrm{s}$ intervals. The total energy required to rotate the conditioning blade at different gas velocities was used as an 183 indication of how well the powder flows when air is entrained and how easily it can be fluidized [40]. 184 For a well flowing and easily fluidizing powder, higher gas velocities will support the powder bed weight and result in significantly lower total energy values required to rotate the conditioning blade. Very cohesive powders with poor fluidization characteristics will tend to form channels in the presence of a gas flow. As a result the gas will be incapable of supporting the powder bed and ultimately the total energy values will remain high. The aeration ratio compares the energy necessary to pass a conditioning blade along a helical path of $5^{\circ}$ at a velocity of $2.0 \mathrm{~cm} / \mathrm{s}$ with and without flowing air.

In the conventional de-fluidization experiments, about $50 \mathrm{~g}$ of the dry coated, blended, or 191 uncoated powder was charged into a $260 \mathrm{~mL}$ glass cylinder (50 $\mathrm{mm}$ diameter) fitted with a stainless 192 steel distributor plate. This apparatus is similar to that used in the aeration test except for the larger 193 dimension. Nitrogen gas was passed through the distributor plate and into the powder bed at various 
superficial gas velocities, and at each velocity the bed height and pressure drop across the bed was

195 recorded. Gas velocities were controlled in the direction of high to low velocities to avoid the hysteresis 196 that can occur near the minimum fluidization velocity [41]. The normalized pressure drop, defined as

197 the ratio of the pressure drop across the bed, DP, to the bed weight divided by the cross sectional area, 198 was plotted as a function of gas velocity to identify the minimum fluidization velocity, $u_{m f}$, and the 199 complete fluidization velocity, $\mathrm{u}_{\mathrm{cf}}$. As described by Gauthier et al. [42] the complete fluidization velocity 200 is the minimum velocity required to achieve a corresponding pressure ratio equal to 1 . The minimum 201 fluidization velocity is an extrapolation of the pressure ratio to the gas velocity in the fixed bed region. 202 This process was repeated several times until the minimum fluidization velocity could be determined 203 with a tolerance of $0.1 \mathrm{~cm} / \mathrm{s}$. Prior to de-fluidization experiments, the pressure drop across distributor 204 plate was measured at various gas velocities in the absence of powder, and subtracted from the 205 pressure drop across the bed.

Particle size was measured using the Rodos/Helos (Sympatec, NJ, USA) venturi based dry

207 powder disperser in conjunction with a laser scattering based particle size analyzer. All measurements 208 were performed at a low dispersion pressure of 0.1 bar to avoid excessive attrition or deagglomeration 209 of the particles at various different stages of coating (uncoated, dry coated, fluid bed coated). To 210 characterize the surface morphology of the ibuprofen at various stages of coating, electron micrographs 211 of the dry coated and fluid bed coated powders were taken using a field emission scanning electron 212 microscope (SEM, Leo 1530 VP, Carl Zeiss, Inc., Peabody, MA, USA).

\section{$213 \quad$ Fluid Bed Coating}

Dry coated ibuprofen (150 g) was charged into the fluid bed bowl of a Mini-Glatt 9550 fluidized

215 bed coating system (Glatt Air, Mahwah, NJ, USA). Air heated to $55-72{ }^{\circ} \mathrm{C}$ was fed through the bottom 216 of the conical fluidized bed, through a stainless steel sintered metal distributor plate with a $5 \mu \mathrm{m}$ pore 
217 size (Mott Corporation, CT, USA). The fluidization velocity was in the range of $3.2-6.4 \mathrm{~cm} / \mathrm{s}$. The Mini-

218 Glatt 9550 has a limited range of possible fluidization velocities and was slightly modified to achieve

219 these low fluidization velocities. Air was partially diverted through the lower nozzle inlet indicated in

220 Figure 1 so that the low flow heater fail-safe was not triggered. This minor modification was necessary

221 so that heated air could not be used below a fluidization velocity of about $12 \mathrm{~cm} / \mathrm{s}$, well above the

222 entrainment velocity of the fine ibuprofen powders. It is emphasized that such modifications would not

223 be required for commercial scale fluidized bed coaters, that are capable of a more complete range of

224 processing conditions. Blowout air was pulsed through $10 \mu \mathrm{m}$ filter cartridges at the top of the fluidized

225 bed every 5 seconds to dislodge powder that may have stuck to the filter. It is noted that the conical

226 configuration is essential to fluidize these fine powders having such a wide size distributions to ensure

227 that the larger particles can be fluidized without elutriating the finer particles. A complete description

228 of the hydrodynamics of a conical fluidized bed is outside the scope of this study can be found in the

229 literature $[43,44]$

The bed was heated to $28^{\circ} \mathrm{C}$ after which a spraying suspension was pushed with a peristaltic 231 pump through a concentric nozzle at the top of the bed with an inner nozzle $(300 \mu \mathrm{m})$ at a spray rate of $2321.00-1.26 \mathrm{~mL} / \mathrm{min}$. Several spraying suspension formulations were considered in this study, which are

233 listed in Table 2. The spray was atomized into droplets by unheated compressed air fed through the 234 outer nozzle $(800 \mu \mathrm{m})$ at 1.00 bar pressure. The bed temperature was closely monitored and the inlet 235 temperature was modified, if necessary, to ensure that the bed temperature was maintained at $26 \pm$ $2361^{\circ} \mathrm{C}$. Additionally, a pneumatically powered vibrator was mounted to the column wall to dislodge 237 particles stuck to the wall. 
a predetermined suspension volume. The spray was turned off and the bed was dried for several minutes until the bed temperature was above $28^{\circ} \mathrm{C}$, at which point the fluidizing air as well as atomizing air were also stopped. The bed was opened and inspected for signs of excessive agglomeration, ratholes or caking on the filters. About 3-5 g of sample was collected for sizing and imaging purposes. This process was repeated until the total polymer suspension had been sprayed after which the powder in the bowl was collected.

\section{Results and Discussion}

\section{Powder Flow and Fluidization Characterization}

The flow and fluidization behavior of the uncoated, V-blended and dry coated IBU50 (74 $\mu \mathrm{m}$ size) powders were characterized to determine the influence of the presence of nano-silica particles on the drug particle surface. Several properties as measured are listed in Table 3. It can be seen that the flow properties of the ibuprofen powders were greatly improved by the presence of nano-silica distributed by both v-blending and acoustic mixing, as shown by the drastic decrease in the angle of repose (AOR) and increase in the flow function coefficient (FFC) listed in Table 3. The AOR values drastically decrease from $55^{\circ}$ for the uncoated ibuprofen to $41^{\circ}$ and $39^{\circ}$ for the v-blended and LabRAM dry-coated ibuprofen indicating a significant improvement in the powder flow properties [6, 37, 45-47]. Similarly, the FFC values significantly increased from 4 to greater than 10 , which indicates that they are freely flowing [39] after the addition of the nano-silica particles. These results coincide with the previous findings $[6,24-26,30,31]$, which show that the addition of silica can significantly improve the flowability of these cohesive powders. Similar to the current results, previous studies have demonstrated that in some cases, the addition of nano-silica particles through low intensity methods (i.e. hand mixing or v-blending) can offer substantial flow improvements, although high intensity dry 
coating performed by MAIC [24, 30-34], LabRAM [26], or Fluid Energy Milling [6, 27] leads to better improvements. As mentioned before, Yang et al. proposed that the flow improvements were due to the introduction of nano-sized surface asperities in the form of the guest particle [24]. Chen et al. later showed that the surface area coverage of the surface asperities introduced by dry coating as well as the surface energy play a significant role in the flow improvement [30]. SEM images of the uncoated, $v$ blended, and dry coated ibuprofen powders, depicted in Figure 2, show that their surfaces are very different; the uncoated powders are smooth, while the v-blended show nano-silica particles less evenly coated and have a rougher surface as compared to dry coated particles that have nano-silica particles distributed more evenly and smoothly, although they naturally appear to be nano-rough.

The fluidization properties of the uncoated, blended, and dry coated ibuprofen powder are listed in Table 3. The total energy consumed during each aeration test was plotted as a function of air velocity in Figure 3. The energy profile of the uncoated ibuprofen was nearly flat, without the characteristic reduction in the total energy or high aeration ratio, indicating the powder could not be fluidized. On the other hand, both nano-silica containing ibuprofen powders show a dramatic reduction in the total energy for gas velocities from $0-0.4 \mathrm{~cm} / \mathrm{s}$. The rapid decrease in energy with increasing velocity due to the lubricating effect of the fluidizing air; the energy ultimately decreases to a very low value, resulting in a large aeration ratio, indicating that the powder is highly sensitive to the presence of air [40]. At high velocities the energy profile for the non-cohesive powders will generally plateau indicating that such powders can be fluidized [48].

The energy profile of the dry coated ibuprofen (DC-74) shows that after a first initial drop the energy consumed was constant. The v-blended ibuprofen (VB-74) shows a gradual decrease after a first initial drop and ultimately plateaus at a much higher velocity, which suggests that its powder could fluidize, but only at a larger velocity than DC-74. 
pressure drop values reached 1 for the powders containing nano-silica; hence can indeed be fluidized, whereas the uncoated IBU50 cannot. The minimum fluidization and complete fluidization velocities of the v-blended ibuprofen were slightly larger than the dry coated samples, which were also observed in the aeration test energy profiles. These high characteristic velocities likely result from the presence of large agglomerates of ibuprofen still present in the non-dry coated blend. The low intensity blending method was incapable of exerting the necessary forces to break the ibuprofen agglomerates that are naturally present during the processing, such as sieving that was required before blending with nanosilica. The LabRAM, on the other hand, produces intense particle-particle and particle-wall collisions, capable of breaking up large agglomerates, without attriting the particles yet simultaneously distributing the nano-silica particles across the API surface. Additionally it is noted that the dry coated powder was prepared without pre-sieving, thus removing a time consuming extra processing step.

Next, the IBU90 particles milled down to $41 \mu \mathrm{m}$ powders were considered. The SEM images of the micronized and uncoated, v-blended or dry coated $41 \mu \mathrm{m}$ powders are shown in Figure 5 . Figure 5a shows that without a nano-silica coating, the ibuprofen particles form agglomerates that are difficult to disperse. The ibuprofen particles v-blended with nano-silica show that undispersed silica agglomerates are attached to the surface of the unbroken ibuprofen agglomerates, as depicted in Figure 5c. The simple blend prepared by the v-blender was unable to disperse the nano-silica and ibuprofen particles (in Figure 5a), offers similar levels of agglomeration to the uncoated powder (in Figure 5c) and therefore did not offer a significant processing benefit. On the other hand images of the dry coated ibuprofen shown in Figure 5b indicate well coated and well dispersed ibuprofen particles, indicating that the acoustic mixing was capable of dispersing the particles, while the nano-silica dry coating was able to prevent further agglomeration. The lack of agglomeration and easy dispersion for dry coated powders is expected to lead to improved flow and fluidization behavior. The formation of these large agglomerates 
after the milling process without dry coating was observed by others and is often an unintended side

310 effect of milling processes. In addition to a reduction in particle size, the milling processes can

311 potentially introduce high energy sites, which can have detrimental effects on the behavior of the milled

312 particles in terms of both powder handling and performance due to the high relative cohesion [6, 49].

313 Fortunately, acoustic mixing was able to exert the necessary forces to break up these ibuprofen

314 agglomerates and distribute the nano-silica particles to avoid further agglomeration during dry coating.

315 As discussed next, the milled IBU90 particles that were dry coated by acoustic mixing fluidized nicely

316 without channeling or the observance of large agglomerates and allowed for significant bed expansion.

Flow and fluidization behaviors for the micronized ibuprofen powders with and without nano-

318 silica are presented in Table 4 and Figures 6 and 7. Without nano-silica, the milled ibuprofen (UC-41)

319 had much higher AOR values and much lower FFC values, indicating a highly cohesive and poorly flowing

320 powder. Similarly the uncoated and milled ibuprofen could not be fluidized and was nearly insensitive

321 to aeration. The AOR and FFC values, shown in Table 4, indicate that the introduction of nano-silica

322 through v-blending and acoustic mixing was capable of improving the powder flow properties, although

323 dry coating led to more significant increase in the FFC values. Similar to $74 \mu \mathrm{m}$ ibuprofen, the AOR

324 results do not discern the property improvements between V-blended and dry coated powders, 325 although the FFC does, in particular for the finer ibuprofen powder.

Aeration tests for the micronized ibuprofen with and without nano-silica showed that the 327 presence of nano-silica makes the micronized ibuprofen significantly more sensitive to aeration. This 328 can be seen in both the high aeration ratios listed in Table 4 
Table 4 and the energy profiles, as depicted in Figure 6, show that the micronized ibuprofen was

330 significantly sensitive to the presence of air when either of the nano-silica addition methods was used.

331 After a first initial drop, the energy profile plateaued for the dry coated micronized ibuprofen (DC-41),

332 again suggesting the powder should be fluidizable. On the other hand, the energy profile of the v-

333 blended powder (VB-41) continued to gradually decrease across all velocities values, and it did not reach

334 plateaue suggesting that the powder may not be fluidizable. These results correspond well with the FFC

335 values, and also the SEM images shown in Figure 5, which indicated the presence of ibuprofen

336 agglomerates in the uncoated and v-blended powders.

The de-fluidization experiments show similar results. As shown by Figure 7, both the uncoated

and v-blended milled ibuprofen did not achieve a pressure drop ratio of 1 . Additionally, severe

channeling was observed during the de-fluidization experiment and millimeter-sized ibuprofen

agglomerates were found settled on the distributor plate. The results suggest that only a portion of the

powder could be supported by gas flow and that the rest of the powder existed in the form of large agglomerates.

\section{Fluid Bed Coating}

Ibuprofen powders of sizes 74 and $41 \mu \mathrm{m}$ were fluid bed coated in a bench-scale conical

fluidized bed coater at a variety of processing conditions and using various spraying suspensions to

347 fluidization velocity, the presence of colloidal silica, its size, its stability and the ibuprofen particle size on

348 agglomeration will be investigated. Based on the de-fluidization experiments performed in the previous 


\section{The Effect of Fluidization Velocity on Agglomerate Size}

DC-74 was fluid bed coated with spraying suspension S1, at a constant sprayrate of $1.25 \mathrm{~mL} / \mathrm{min}$ and at varying fluidization velocities ranging from $4.3-6.4 \mathrm{~cm} / \mathrm{s}$ to determine the fluidization velocity that minimizes agglomeration. This is the most basic polymer solution used for spray coating, and it only contains polymers dissolved in a solvent mixture. The growth of the ibuprofen particle size with respect to the polymer loading is depicted in Figure 8 , where the growth is presented as the ratio of the volume averaged $d_{90}$ before and after coating the corresponding amount of polymer was sprayed. The intent is to achieve very good film coating, while keeping agglomeration to a low level. It can be seen that an optimum fluidization velocity with respect to agglomeration is $5.3 \mathrm{~cm} / \mathrm{s}$. The lower fluidization velocities were not capable of sufficiently drying the bed and ultimately defluidized after the ibuprofen was coated with only $2.5 \%$ polymer [4]. Higher fluidization velocities, on the other hand, resulted in drier conditions which again promoted significant agglomeration through electrostatic charging [50], as well as the elutriation of the fine particles due to the high fluidization velocity. Even though the agglomerate sizes at the higher and lower velocities were the same, the bed only de-fluidized at the lower velocity, because there was not enough air flow to support the weight of the newly formed agglomerates due to their increased size [3].

\section{The Effect of the Presence of Colloidal Silica, and Colloid Stability}

Based on these results a fluidization velocity of $5.3 \mathrm{~cm} / \mathrm{s}$ was used to study the effect of the presence and stability of colloidal silica in the spray suspension. This was accomplished by introducing colloidal silica particles in different $\mathrm{pH}$ environments, as can be seen in different suspension formulations in Table 2. The purpose of added colloidal silica is to reduce agglomeration during fluid bed coating. The colloidal silica particles encased in the film coating will introduce asperities to the polymer coated ibuprofen to reduce cohesion, create separation between the core particles, and ultimately prevent agglomeration during spray coating. Several other authors have shown that 
agglomeration can be minimized when colloidal dispersions are sprayed instead of polymeric solutions

$377[51,52]$. Figure 9 shows that the presence of the $180 \mathrm{~nm}$ colloidal silica particles allowed for higher coating weight gains without significant agglomeration. The surfaces of these polymer coated ibuprofen particles can be seen in Figure 10 a-d, showing magnified SEM images of the coated surface without and with the colloidal silica coating, respectively. Figure 10a depicts the surface of an ibuprofen particle coated with suspension S1 (without silica); with the exception of some spray dried polymer particles the surface is nearly free of any asperity. Figure $10 \mathrm{~b}$ is the zoomed out version, which shows the severe agglomeration observed in Figure 9. The surface of an ibuprofen particle coated with suspension S2 (with silica) is shown in Figure 10c,d. The presence of the silica particles is evident, which offered asperities capable of reducing agglomeration, as shown by Figure 9 and the well dispersed particles in Figure 10d.

Even though there was an agglomeration reduction, it was noticed that there were still significant processing problems. Appreciable spray drying can be observed in Figure $10 \mathrm{c}, \mathrm{d}$ and it is due to the poor stability of the colloidal silica particles in the spraying solution. During the coating experiment the unstabilized colloidal silica particles would sediment within the nozzle resulting in poor spray rate control and ultimately the complete clogging of the nozzle. This clogging, which was not observed with suspension S1, introduced a time consuming cleaning step and required constant supervision. Additionally the excessive spray drying that occurred due to the flow obstruction 394 introduced by the colloidal silica would lead to poor polymer distributions and non-uniform coatings. 395 While the presence of this colloidal silica is capable of decreasing the final agglomerate size, the difficulty in processing makes this addition undesirable. mentioned nozzle clogging issues. Three formulations ( $33, \mathrm{~S} 4$ and $\mathrm{S} 5$ ) were prepared to determine the 
effect of the $\mathrm{pH}$ modification on the agglomeration of the ibuprofen particles during fluid bed coating.

These suspensions, along with suspension S2, were fluid bed coated onto dry coated ibuprofen at the same coating conditions, and the growth with respect to polymer loading is shown in Figure 11. In all cases, the use of the $\mathrm{pH}$ modifier eliminated nozzle clogging and severe spray drying issues. It can be seen that coating with suspension S5 led to a comparable growth profile as when no stabilizer was used (suspension S2), whereas suspensions S3 and S4 led to significant agglomeration. Agglomerate size in each suspension was determined using dynamic light scattering (DLS, DelsaNano, Beckmann Coulter, NJ, USA). Three successive size measurements were performed immediately after preparation of the suspension. The average and standard deviation of these measurements are listed in Table 5 . There is significant variability in the sizes for S3 and S4 suggesting that they may not be stable and the colloidal silica agglomerates will grow over time. The lower variability in suspension S5 is likely due to the colloidal silica's improved electrostatic stabilization at a higher $\mathrm{pH}$. It can be seen that the suspension with the smallest colloidal silica agglomerate size and the least variability led to the least growth during

412 fluidized bed coating. A representative SEM image of an ibuprofen particle coated with suspension S5 is 413 presented in Figure 12 and shows that the colloidal silica particles are present and well dispersed 414 throughout the polymer film layer in a similar way as to when no stabilizer is used (suspension S2, 415 presented in Figure 10), but without the undesired spray drying.

The use of suspensions S3 and S4 led to significantly faster size growth during fluid bed coating.

417 The close up SEM images shown in Figure 13a,c reveal that $\sim 1$ and $\sim 4 \mu \mathrm{m}$ colloidal silica agglomerates 418 were present in the polymeric layer for suspensions S3 and S4, respectively. This finding is in agreement 419 with the suspension agglomerate size results in Table 5. In the zoomed out SEM images in Figure 13b,d 420 it can be seen that these agglomerates are poorly dispersed throughout the polymer coating leaving 421 areas that are devoid of these cohesion reducing colloidal silica particles. These results indicate that the 422 colloidal silica particles were being stabilized as agglomerates and could not adequately be dispersed 
423 through the polymer layer, which resulted in a coating layer more comparable to when S1 was used

424 (when no colloidal silica was present) than S2 or S5 where the colloidal silica particles were dispersed

425 effectively. These results are comparable to the findings of Hede et al. who observed that improved

$426 \mathrm{TiO}_{2}$ dispersion in a PVA solution decreased the "stickiness" of the suspension, and in turn reduced

427 agglomeration of $400-500 \mu \mathrm{m}$ sodium sulfate beads [52].

Using the optimized spraying suspension determined above (suspension S5) the effect of the

429 fluidization velocity was re-evaluated. Figure 14 depicts the d90 ratio as a function of polymer loading

430 and shows that decreasing the superficial fluidization velocity to $4.3 \mathrm{~cm} / \mathrm{s}$ can lead to significantly less

431 agglomeration than when the higher velocity was used. In the earlier experiment with suspension S1,

432 the lower velocity led to defluidization due to severe agglomeration. However the optimized sparying

433 suspension (S5) was able to minimize agglomeration and prevent defluidization. Furthermore the

434 reduced gas velocity diminished size growth due to decreases in the elutriation and triboelectrification.

435 An increase in product yield, from 73 to $88 \%$, at the lower velocity, confirms that more fines were

436 indeed being elutriated at the higher fluidization velocity.

437 Fluidized Bed Coating of Micronized Ibuprofen

$438 \quad$ Based on the optimized fluid bed coating processing conditions of DC-74, the micronized and dry

439 coated ibuprofen, DC-41, was fluid bed coated. To minimize process optimization experiments at this

440 lower particle size, the excess fluidization velocity was used to scale down the fluidization velocity,

441 which was then used to scale down the spray rate. The excess velocity, described in Eq (1), is the

442 difference between the superficial fluidization velocity, $u_{s f}$ and the complete fluidization velocity, $u_{c f}$.

443 Considering the difference in particle size between DC-41 and DC-74, the superficial gas velocity should

444 be reduced to avoid the elutriation of fine particles. In these experiments the excess velocity was

445 reduced proportionately by the ratio of the DC-41 and DC-74 complete fluidization values, as described

446 by Equation 2. Using Eq (1) and Eq (2), a suitable value for $\mathrm{u}_{\mathrm{sf}}$ was determined to be $3.2 \mathrm{~cm} / \mathrm{s}$. Based on 
447 this velocity, the sprayrate was lowered to $1.0 \mathrm{~mL} / \mathrm{min}$ (proportionally to $\mathrm{u}_{\mathrm{sf}}$ ) to avoid excessively wet or 448 dry conditions, both of which have been shown to cause unwanted agglomeration.

449

450

$\mathrm{Eq}(1) \quad u_{e x}=u_{s f}-u_{c f}$

Eq (2) $u_{e x, D C-41}=u_{e x, D C-74} \times\left(u_{c f, D C-41} / u_{c f, D C-74}\right)$

A comparison of the $\mathrm{d} 90$ ratio for DC-41 and DC-74 at different polymer loadings is presented in Figure 15. It can be seen that minimal agglomeration was achieved with fluid bed coating of the micronized ibuprofen. Additionally, it can be seen that the $d_{90}$ ratio of the DC- 41 is nearly identical to that of DC-74 indicating that the scaling method used to determine the fluid bed coating parameters offered a useful first approximation. It can also be seen by the size statistics in Table 6 that the size distribution significantly narrowed during the coating process, most likely due to the slight growth of the smallest particles, while the largest particles are mostly unchanged. The size growth results may be confirmed by the cumulative size distributions shown in Figure 16 and the high and low magnification SEM images of the DC-74 and DC-41 depicted in Figure 17. Figure 16a,b show that the unmilled DC-74 were mostly individually polymer coated particles with only minimal agglomeration after coating with a $10 \%$ polymer loading. Figure $17 \mathrm{c}$, d shows that when the smaller micronized powders (DC-41) were coated there was some agglomeration of the smallest particles, but larger particles were largely unaffected. Ultimately this results in a powder less prone to segregation and is therefore easier to handle in downstream processes. Even with this growth, the particle sizes of the coated particles are still far smaller than what is typically attempted as the starting size in the literature for API materials.

\section{Conclusions}

Ibuprofen powders with $d_{50}$ sizes of 41 and $74 \mu \mathrm{m}$ (Sauter mean diameters of 21 and $42 \mu \mathrm{m}$ ) were polymer film coated in a top spray fluidized bed with minimal agglomeration. The current study 
builds on our previous work where surface modification of Geldart group C powders with nano-silica

470 nanoparticles was done to reduce the cohesion and sufficiently enhance the flow and fluidization

471 properties of cornstarch and aluminum particles to polymer film coat them in a top spray fluidized bed.

472 To the authors' knowledge, the present study is the first reported attempt to achieve similar film coating

473 of micronized drug powders, which are far more challenging due to their irregular shape, wide size

474 distributions, high surface energy and propensity for tribocharging. Modifications to the spraying

475 suspension were required and introduced to handle such complexies of the pharmaceutical powders.

The current study shows that for drug powders, nano-silica dry coating alone is not sufficient. It

477 was found that the ibuprofen powders would severely agglomerate or defluidize after polymer coating

478 without the presence of large colloidal particles in the polymer layer that could reduce agglomeration

479 during coating. Colloidal silica particles of $180 \mathrm{~nm}$ size, stabilized with $\mathrm{NaOH}$ in the polymer spray

suspension were necessary to reduce agglomeration. With unstabilized colloidal silica or without

481 colloidal silica, agglomeration levels were significantly larger due to the lack of well dispersed asperities

482 in the polymer surface.

Spray rate and fluidization velocity were studied to understand their effect on agglomeration of

484 the ibuprofen powders. As expected, increased spray rate led to increased agglomeration due to poor

485 drying conditions. Higher fluidization velocities are typically employed to enhance drying and counter

486 balance high spray rates, however increased fluidization velocities also led to increased agglomeration

487 resulting from electrostatic charging. Optimizing these processing conditions was required to ensure

488 minimal agglomeration of the ibuprofen powders and can often be time consuming. A simple scaling

489 relationship was introduced to approximate desirable coating conditions across different particle sizes.

490 This relationship was used to predict the coating conditions for micronized ibuprofen powders, based on

491 the conditions optimized for the coarse ibuprofen powders. 
492 Acknowledgements: The authors gratefully acknowledge partial financial support from Catalent Pharma

493 Solutions as well as National Science Foundation (awards, EEC-0540855, DGE-0504497, and IIP494 1312125).

495 


\section{Nomenclature}

497

$498 \quad d_{10} \quad$ Volume based cumulative diameter that represents the lower $10 \%$ of the size distribution $(\mu \mathrm{m})$

$499 \quad d_{50} \quad$ Volume based cumulative diameter that represents the lower $50 \%$ of the size distribution $(\mu \mathrm{m})$

$500 \quad d_{90} \quad$ Volume based cumulative diameter that represents the lower $90 \%$ of the size distribution $(\mu \mathrm{m})$

$501 \quad$ FFC Flow function coefficient

$502 \quad u_{e x} \quad$ Excess fluidization velocity $(\mathrm{cm} / \mathrm{s})$

$503 \quad u_{s f} \quad$ Superficial fluidization velocity $(\mathrm{cm} / \mathrm{s})$

$504 \quad u_{e x} \quad$ Complete fluidization velocity $(\mathrm{cm} / \mathrm{s})$

505

506 
1. Werner, S.R.L., et al., Air-suspension coating in the food industry: Part II - micro-level process approach. Powder Technology, 2007. 171(1): p. 34-45.

2. Werner, S.R.L., et al., Air-suspension particle coating in the food industry: Part I - state of the art. Powder 511 Technology, 2007. 171(1): p. 25-33.

3. Teunou, E. and D. Poncelet, Batch and continuous fluid bed coating - Review and state of the art. Journal of Food Engineering, 2002. 53(4): p. 325-340.

4. Dixit, R. and S. Puthli, Fluidization technologies: Aerodynamic principles and process engineering. Journal of

5. Bilgili, E., et al., Experimental study of fluidized bed co-granulation of two active pharmaceutical ingredients: An industrial scale-up perspective. Particulate Science and Technology, 2011. 29(3): p. 285-309.

6. Han, X., et al., Simultaneous micronization and surface modification for improvement of flow and dissolution of drug particles. International Journal of Pharmaceutics, 2011. 415(1-2): p. 185-195.

7. Dewettinck, K. and A. Huyghebaert, Top-Spray Fluidized Bed Coating: Effect of Process Variables on Coating

8. Geldart, D., Types of gas fluidization. Powder Technology, 1973. 7(5): p. 285-292.

9. Ehlers, H., et al., Granule size control and targeting in pulsed spray fluid bed granulation. International Journal of Pharmaceutics, 2009. 377(1-2): p. 9-15.

10. Takano, K., K. Nishii, and M. Horio, Binderless granulation of pharmaceutical fine powders with coarse lactose for

11. Thiel, W.J. and L.T. Nguyen, Fluidized bed granulation of an ordered powder mixture. Journal of Pharmacy and

12. Shen, R.W., Taste Masking of Ibuprofen by Fluid Bed Coating, U.S.P. Office, Editor 1996, The Upjohn Company: US. 
14. Kawaguchi, T., et al., Granulation of acetaminophen by a rotating fluidized-bed granulator. Pharmaceutical Development and Technology, 2000. 5(2): p. 141-151.

15. Watano, S., et al., Microgranulation of fine powders by a novel rotating fluidized bed granulator. Powder Technology, 2003. 131(2-3): p. 250-255.

16. Watano, S., et al., Fine particle coating by a novel rotating fluidized bed coater. Powder Technology, 2004. 141(3): p. 172-176.

17. Hamashita, T., et al., Granulation of core particles suitable for film coating by agitation fluidized bed II. A proposal of a rapid dissolution test for evaluation of bitter taste of ibuprofen. Chemical and Pharmaceutical Bulletin, 2008. 56(7): p. 883-887.

18. Hamashita, T., et al., Granulation of core particles suitable for film coating by agitation fluidized bed I. Optimum formulation for core particles and development of a novel friability test method. Chemical and Pharmaceutical Bulletin, 2007. 55(8): p. 1169-1174.

19. Hamashita, T., et al., Granulation of core particles suitable for film coating by agitation fluidized bed iii. effect of scale, agitator rotational speed and blade shape on granule properties and development of a high accuracy scaleup theory. Chemical and Pharmaceutical Bulletin, 2009. 57(4): p. 325-331.

20. Miyadai, N., et al., Optimization and characterization of direct coating for ibuprofen particles using a composite fluidized bed. Advanced Powder Technology, (0).

21. Jono, K., et al., A review of particulate design for pharmaceutical powders and their production by spouted bed coating. Powder Technology, 2000. 113(3): p. 269-277.

22. Fukumori, Y., et al., Microgranulation and encapsulation of pulverized pharmaceutical powders with ethyl cellulose by the Wurster process. Chemical and Pharmaceutical Bulletin, 1991. 39(7): p. 1806-1812.

23. Jesse, Z., Hui Zhang, Fluidization additives to fine powders, U.S.P. Office, Editor 2002, The University of Western Ontario: United States.

24. Yang, J., et al., Dry particle coating for improving the flowability of cohesive powders. Powder Technology, 2005. 158(1-3): p. 21-33.

25. Mullarney, M.P., et al., Applying dry powder coatings to pharmaceutical powders using a comil for improving powder flow and bulk density. Powder Technology, 2011. 212(3): p. 397-402.

26. Mullarney, M.P., et al., Applying dry powder coatings: Using a resonant acoustic mixer to improve powder flow and bulk density. Pharmaceutical Technology Europe, 2011. 23(10): p. 16-23. 
27. Zhang, Q., et al., In-situ, simultaneous milling and coating of particulates with nanoparticles. Powder Technology, 2009. 196(3): p. 292-297.

28. Chattoraj, S., L. Shi, and C.C. Sun, Profoundly improving flow properties of a cohesive cellulose powder by surface coating with nano-silica through comilling. Journal of Pharmaceutical Sciences, 2011. 100(11): p. 4943-4952.

29. Koichi Inoue, Y.N., Hitoshi Nakatsuka, Easily sievable powder coating composition, U.S.P. Office, Editor 1999, Nippon Paint Co., Ltd. .

30. Chen, Y., et al., Characterization of particle and bulk level cohesion reduction of surface modified fine aluminum powders. Colloids and Surfaces A: Physicochemical and Engineering Aspects, 2010. 361(1-3): p. 66-80.

31. Chen, Y., et al., Fluidization of coated group C powders. AIChE Journal, 2008. 54(1): p. 104-121.

32. Chen, Y., et al., Fluidized bed film coating of cohesive Geldart group C powders. Powder Technology, 2009. 189(3): p. 466-480.

33. Beach, L., et al., Near-infrared spectroscopy for the in-line characterization of powder voiding part II: Quantification of enhanced flow properties of surface modified active pharmaceutical ingredients. Journal of Pharmaceutical Innovation, 2010. 5(1-2): p. 1-13.

34. Ropero, J., et al., Near-infrared spectroscopy for the in-line characterization of powder voiding part I: Development of the methodology. Journal of Pharmaceutical Innovation, 2009. 4(4): p. 187-197.

35. Jallo, L.J., et al., Improvement of flow and bulk density of pharmaceutical powders using surface modification. International Journal of Pharmaceutics, 2012. 423(2): p. 213-225.

36. Stober, W. and A. Fink, Controlled growth of monodisperse silica spheres in the micron size range Journal of Colloid Interface Sciences, 1968. 26(1): p. 62-69.

37. ASTM, Standard Test Method for Bulk Solids Characterization by Carr Indices, 2011, ASTM International: West Conshohocken, PA.

38. Emery, E., et al., Flowability of moist pharmaceutical powders. Powder Technology, 2009. 189(3): p. $409-415$.

39. Schulze, D., Powders and bulk solids: behavior, characterization, storage and flowc2008, Berlin; New York: Springer.

40. Price, R. and T. Freeman, Powder Characterization, Dynamic Powder Characterization for DPI formulations. Drug Delivery Technology, 2009. 9(5): p. 50-55.

41. Davidson, J.F., Fluidization. 2nd ed ed1985, London, Orlando: Academic Press. 
42. Gauthier, D., S. Zerguerras, and G. Flamant, Influence of the particle size distribution of powders on the velocities of minimum and complete fluidization. Chemical Engineering Journal, 1999. 74(3): p. 181-196.

43. Murthy, J.S.N., et al., Hydrodynamics of gas-solid fluidization in tapered beds. Canadian Journal of Chemical Engineering, 2009. 87(3): p. 359-374.

44. Shi, Y.F., Y.S. Yu, and L.T. Fan, Incipient fluidization condition for a tapered fluidized bed. Industrial and Engineering Chemistry Fundamentals, 1984. 23(4): p. 484-489.

45. Geldart, D., E.C. Abdullah, and A. Verlinden, Characterisation of dry powders. Powder Technology, 2009. 190(1-2): p. 70-74.

46. Lavoie, F., L. Cartilier, and R. Thibert, New methods characterizing avalanche behavior to determine powder flow. Pharmaceutical Research, 2002. 19(6): p. 887-893.

47. Thalberg, K., D. Lindholm, and A. Axelsson, Comparison of different flowability tests for powders for inhalation. Powder Technology, 2004. 146(3): p. 206-213.

48. Pitchayajittipong, C., et al., Characterisation and functionality of inhalation anhydrous lactose. International Journal of Pharmaceutics, 2010. 390(2): p. 134-141.

49. De Villiers, M.M., Influence of agglomeration of cohesive particles on the dissolution behaviour of furosemide powder. International Journal of Pharmaceutics, 1996. 136(1-2): p. 175-179.

50. Guardiola, J., V. Rojo, and G. Ramos, Influence of particle size, fluidization velocity and relative humidity on fluidized bed electrostatics. Journal of Electrostatics, 1996. 37(1-2): p. 1-20.

51. Vecchio, C., F. Fabiani, and A. Gazzaniga, Use of colloidal silica as a separating agent in film forming processes performed with aqueous dispersion of acrylic resins. Drug Development and Industrial Pharmacy, 1995. 21(15): p. 1781-1787.

52. Hede, P.D., P. Bach, and A.D. Jensen, Fluidized-bed coating with sodium sulfate and PVA-TiO2, 2. Influence of coating solution viscosity, stickiness, $\mathrm{pH}$, and droplet diameter on agglomeration. Industrial and Engineering Chemistry Research, 2009. 48(4): p. 1905-1913. 


\section{List of Tables}

618

619 Table 1: Dry Coated and uncoated powders

620 Table 2: Spraying suspension formulations

621 Table 3: Flow and Fluidization properties of $74 \mu \mathrm{m}$ ibuprofen

622 Table 4: Flow and Fluidization properties of $41 \mu \mathrm{m}$ ibuprofen

623 Table 5: Silica agglomerate sizes in suspensions S1, S2, S3, S4 and S5 as measured by dynamic light scattering

624 Table 6: Ibuprofen particle sizes before and after fluid bed coating

625

626

627 
Table 1: Dry Coated and uncoated powders

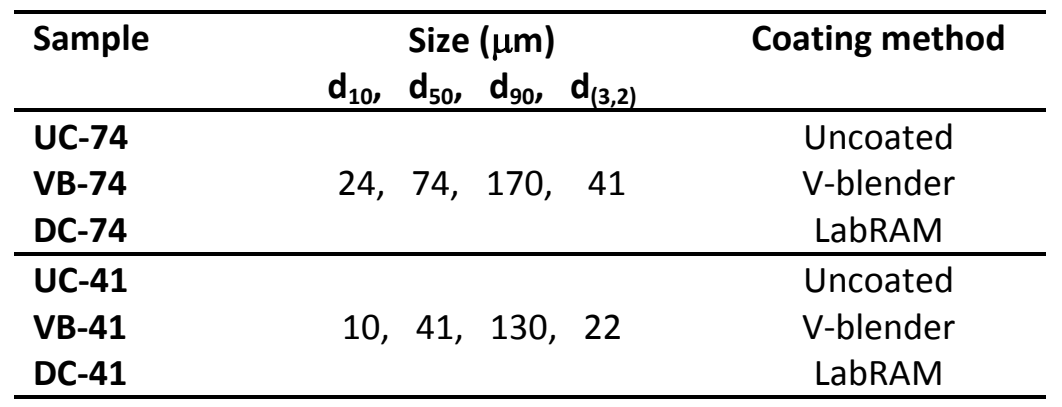

629

630

Table 2: Spraying suspension formulations

\begin{tabular}{|c|c|c|c|c|c|c|c|c|}
\hline \multirow{2}{*}{$\begin{array}{c}\text { Suspension } \\
\# \\
\end{array}$} & \multicolumn{2}{|c|}{ Polymer } & \multicolumn{2}{|c|}{ Silica } & \multicolumn{4}{|c|}{ Solvent } \\
\hline & $\begin{array}{c}\text { RS100 } \\
(\%)\end{array}$ & $\begin{array}{c}\text { HPMC } \\
(\%)\end{array}$ & $\begin{array}{c}180 \mathrm{~nm} \\
(\%)\end{array}$ & $\begin{array}{l}\text { M5P } \\
(\%)\end{array}$ & $\begin{array}{c}\text { EtOH } \\
(\%)\end{array}$ & $\begin{array}{l}\mathrm{H}_{2} \mathrm{O} \\
(\%)\end{array}$ & $\begin{array}{c}\mathrm{NaOH} \\
(\%)\end{array}$ & $\begin{array}{c}\mathrm{HNO}_{3} \\
(\%)\end{array}$ \\
\hline S1 & 1.13 & 1.50 & -- & -- & 53.55 & 43.82 & -- & -- \\
\hline S2 & 1.13 & 1.49 & 0.57 & -- & 53.24 & 43.56 & -- & -- \\
\hline S3 & 1.13 & 1.49 & 0.57 & -- & 53.24 & -- & 43.56 & -- \\
\hline S4 & 1.13 & 1.49 & 0.57 & -- & 53.24 & -- & -- & 43.56 \\
\hline S5 & 1.60 & 2.10 & 0.81 & -- & 66.84 & -- & 28.65 & \\
\hline
\end{tabular}

631

632 Table 3: Flow and Fluidization properties of $74 \mu \mathrm{m}$ ibuprofen

\begin{tabular}{lccc}
\hline Property & $\begin{array}{c}\text { Uncoated } \\
\text { Ibuprofen }\end{array}$ & $\begin{array}{c}\text { Ibuprofen Blended } \\
\text { with 2\% R972p }\end{array}$ & $\begin{array}{c}\text { Ibuprofen Dry Coated } \\
\text { with 2\% R972p }\end{array}$ \\
\hline $\mathrm{d}_{50}(\mu \mathrm{m})$ & 70 & 75 & 74 \\
$\mathrm{AOR}\left({ }^{\circ}\right)$ & $55 \pm 3$ & $41 \pm 1$ & $39 \pm 1$ \\
$\mathrm{FFC}$ & $5 \pm 1$ & $10.8 \pm 0.1$ & $13.2 \pm 0.2$ \\
$\mathrm{AR}$ & 3.2 & 602.7 & 257.0 \\
$\mathrm{u}_{\mathrm{mf}}(\mathrm{cm} / \mathrm{s})$ & N/A & 0.7 & $0.4 \mathrm{~cm} / \mathrm{s}$ \\
$\mathrm{u}_{\mathrm{cf}}(\mathrm{cm} / \mathrm{s})$ & N/A & 1.4 & $1.2 \mathrm{~cm} / \mathrm{s}$ \\
\hline
\end{tabular}

633

634 
Table 4: Flow and Fluidization properties of $41 \mu \mathrm{m}$ ibuprofen

\begin{tabular}{lccc}
\hline Property & $\begin{array}{c}\text { Uncoated } \\
\text { lbuprofen }\end{array}$ & $\begin{array}{c}\text { Ibuprofen Blended } \\
\text { with 2\% R972p }\end{array}$ & $\begin{array}{c}\text { Ibuprofen Dry Coated } \\
\text { with 2\% R972p }\end{array}$ \\
\hline $\mathrm{d}_{50}(\mu \mathrm{m})$ & 41 & 41 & 41 \\
$\mathrm{AOR}\left({ }^{\circ}\right)$ & $58 \pm 1$ & $35 \pm 2$ & $37 \pm 2$ \\
$\mathrm{FFC}$ & $2.8 \pm 0.8$ & $5.7 \pm 0.1$ & $12.0 \pm 0.3$ \\
$\mathrm{AR}$ & $4.3 \pm 0.7$ & $44 \pm 4$ & $23 \pm 7$ \\
$\mathrm{u}_{\mathrm{mf}}(\mathrm{cm} / \mathrm{s})$ & $\mathrm{N} / \mathrm{A}$ & $\mathrm{N} / \mathrm{A}$ & $0.3 \mathrm{~cm} / \mathrm{s}$ \\
$\mathrm{u}_{\mathrm{cf}}(\mathrm{cm} / \mathrm{s})$ & $\mathrm{N} / \mathrm{A}$ & $\mathrm{N} / \mathrm{A}$ & $1.0 \mathrm{~cm} / \mathrm{s}$ \\
\hline
\end{tabular}

636

637 Table 5: Silica agglomerate sizes in suspensions S1, S2, S3, S4 and S5 as measured by dynamic light scattering

\begin{tabular}{|c|c|c|c|c|c|c|c|}
\hline \multirow{2}{*}{$\begin{array}{c}\text { Suspension } \\
\# \\
\end{array}$} & \multicolumn{2}{|c|}{ Polymer } & \multirow{2}{*}{$\begin{array}{c}\text { Silica } \\
\begin{array}{c}180 \mathrm{~nm} \\
(\%)\end{array}\end{array}$} & \multicolumn{3}{|c|}{ Solvent } & \multirow[t]{2}{*}{ Size $(\mu \mathrm{m})$} \\
\hline & $\begin{array}{c}\text { RS100 } \\
(\%)\end{array}$ & $\begin{array}{c}\text { HPMC } \\
(\%)\end{array}$ & & $\begin{array}{c}\text { EtOH } \\
(\%)\end{array}$ & $\begin{array}{c}\mathrm{NaOH} \\
(\%)\end{array}$ & $\begin{array}{c}\mathrm{HNO}_{3} \\
(\%)\end{array}$ & \\
\hline S3 & 1.13 & 1.49 & 0.57 & 53.24 & 43.56 & -- & $3.44 \pm 0.76$ \\
\hline S4 & 1.13 & 1.49 & 0.57 & 53.24 & -- & 43.56 & $1.29 \pm 0.13$ \\
\hline S5 & 1.60 & 2.10 & 0.81 & 66.84 & 28.65 & & $1.22 \pm 0.02$ \\
\hline
\end{tabular}

638

639

640 Table 6: Ibuprofen particle sizes before and after fluid bed coating

\begin{tabular}{lccc}
\hline Sample & $\begin{array}{c}\text { Before Coating } \\
d_{10}, d_{50}, d_{90}, d_{(3,2)}\end{array}$ & & $\begin{array}{c}\text { After } 10 \% \text { polymer loading } \\
d_{10}, d_{50}, d_{90}, d_{(3,2)}\end{array}$ \\
\cline { 2 - 3 } DC-74 & $24,74,170,41$ & & $45,89,189,76$ \\
DC-41 & $10,41,130,22$ & & $32,70,148,57$ \\
\hline
\end{tabular}

641

642 


\section{List of Figures}

Figure 1: Schematic of fluid bed coater (Mini-Glatt 9550, Glatt).

Figure 2: SEM images of IBU50 (a) as received, and after processing with silica in (b) LabRAM dry coating and (c) Vblending.

Figure 3: Total energy consumed by the conditioning blade at various gas velocities for dry coated, uncoated and vblended $74 \mu \mathrm{m}$ powders.

Figure 4: De-fluidization profile of $74 \mu \mathrm{m}$ ibuprofen with and without silica.

Figure 5: SEM images of milled IBU90 (a) before and after processing with silica in (b) LabRAM dry coating and (c) V-blending.

Figure 6: Total energy consumed by the condition blade at various gas velocities for dry coated, uncoated and vblended $41 \mu \mathrm{m}$ powders.

Figure 7: De-fluidization profile of $41 \mu \mathrm{m}$ ibuprofen with and without silica.

Figure 8: $d_{90}$ ratio of DC-74 ibuprofen powders fluid bed coated with suspension S1 at various superficial fluidization velocities.

Figure 9: $d_{90}$ ratio of DC-74 ibuprofen powders fluid bed coated with suspension S1 and S2 at a superficial fluidization velocity of $5.3 \mathrm{~cm} / \mathrm{s}$.

Figure 10: SEM images of the surface of DC-74 ibuprofen after fluidized bed coating (a) with suspension S1, high magnification (without silica), (b) with suspension S1, low magnification (without silica), (c) with suspension S2, high magnification (with silica), and (d) with suspension S2, low magnification (with silica).

Figure 11: $d_{90}$ ratio of DC-74 ibuprofen powders fluid bed coated with suspension S2, S3, S4 and S5 at a superficial fluidization velocity of $5.3 \mathrm{~cm} / \mathrm{s}$.

Figure 12: (a) High magnification and (b) low magnification SEM images of DC-74 ibuprofen after fluid bed coating with stabilized silica suspension S5.

Figure 13: SEM images of the surface of DC-74 ibuprofen after fluid bed coating stabilized silica suspensions (a) S3 zoomed in, (b) S3 zoomed out, (c) S4 zoomed in, (d) S5 zoomed out.

Figure 14: $d_{90}$ ratio of DC-74 ibuprofen fluid bed coated with suspension S5 at superficial gas velocities of 4.3 and $5.3 \mathrm{~cm} / \mathrm{s}$.

Figure 15: $d_{90}$ ratio of DC-74 and DC-41 fluid bed coated with suspension S5. 
Figure 16: Cumulative volume size distributions of dry coated and fluidized bed coated ibuprofen powders at a $10 \%$ weight gain for (a) DC-74 and (b) DC-41.

Figure 17: SEM images of fluidized bed coated ibuprofen at a polymer loading of 10\%; DC-74, (a) high, (b) low; and DC-41, (c) high, (d) low. 


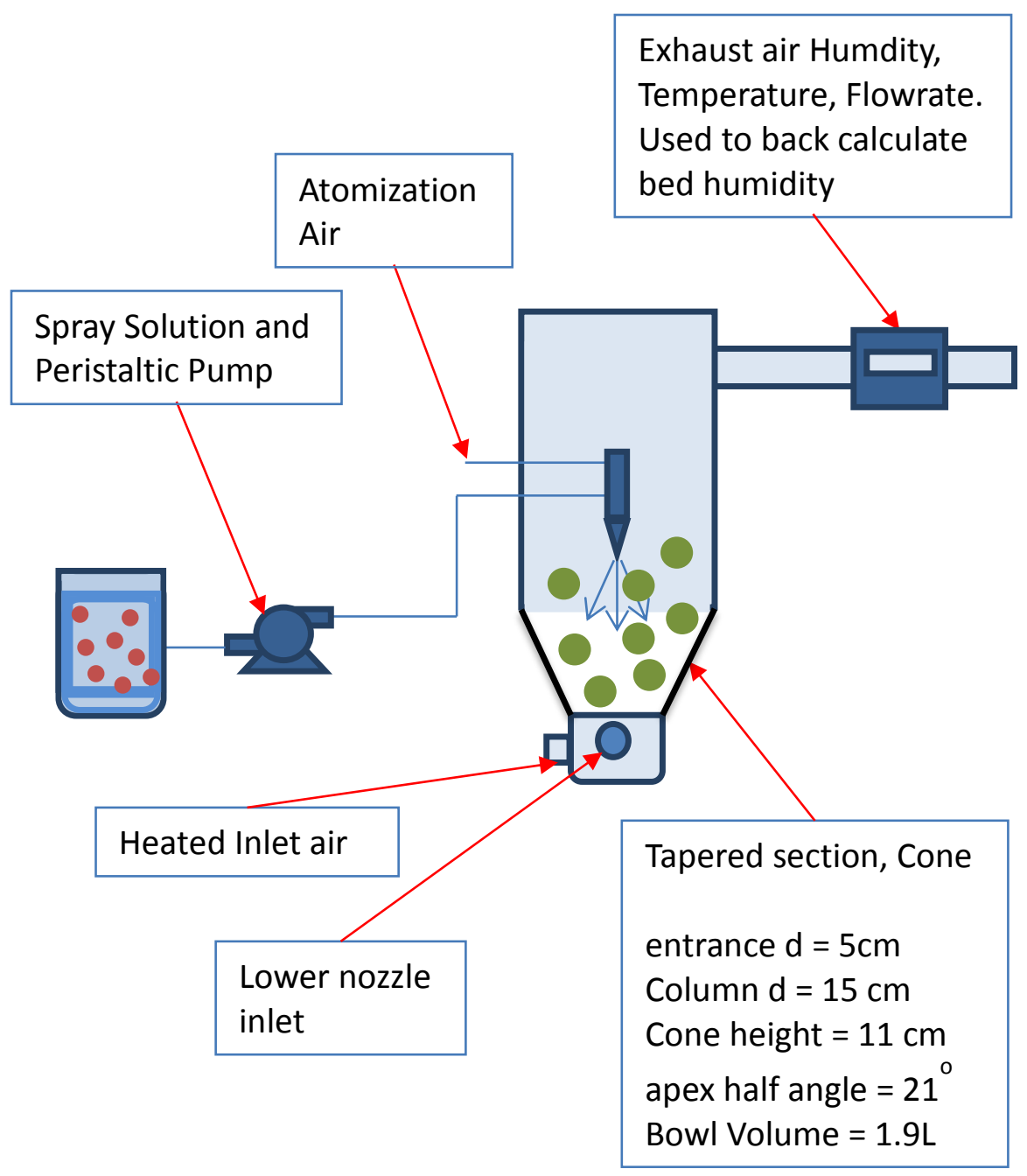

Figure 1: Schematic of fluid bed coater (Mini-Glatt 9550, Glatt). 

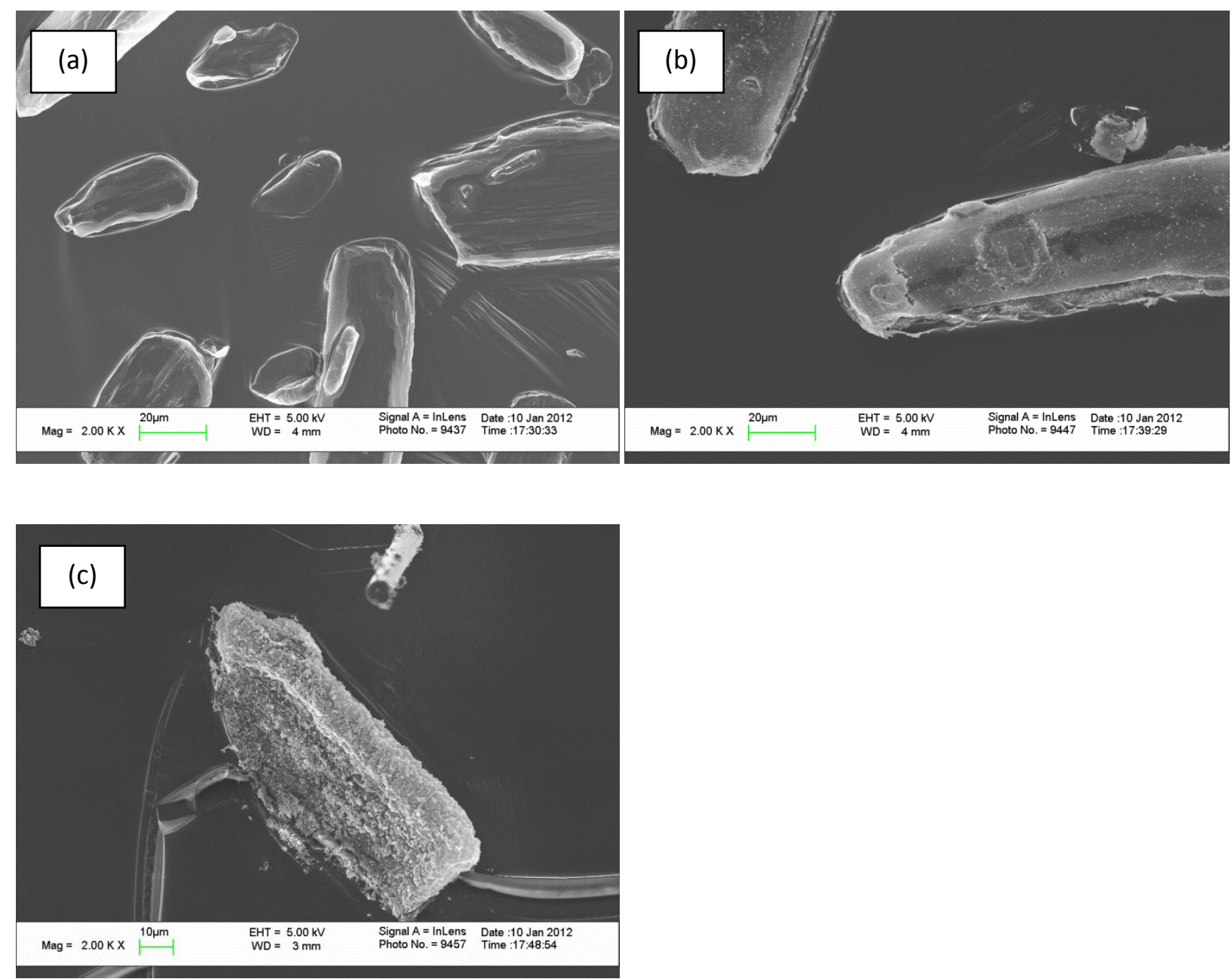

Figure 2: SEM images of IBU50 (a) as received, and after processing with silica in (b) LabRAM dry coating and (c) Vblending. 


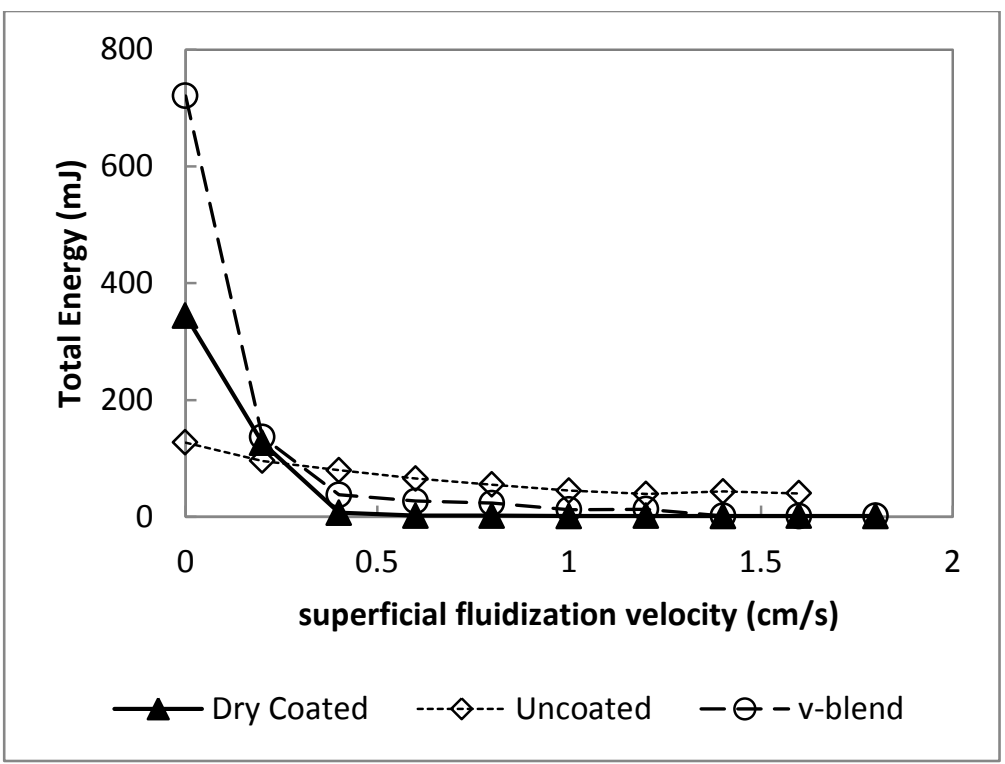

Figure 3: Total energy consumed by the conditioning blade at various gas velocities for dry coated, uncoated and vblended $74 \mu \mathrm{m}$ powders.

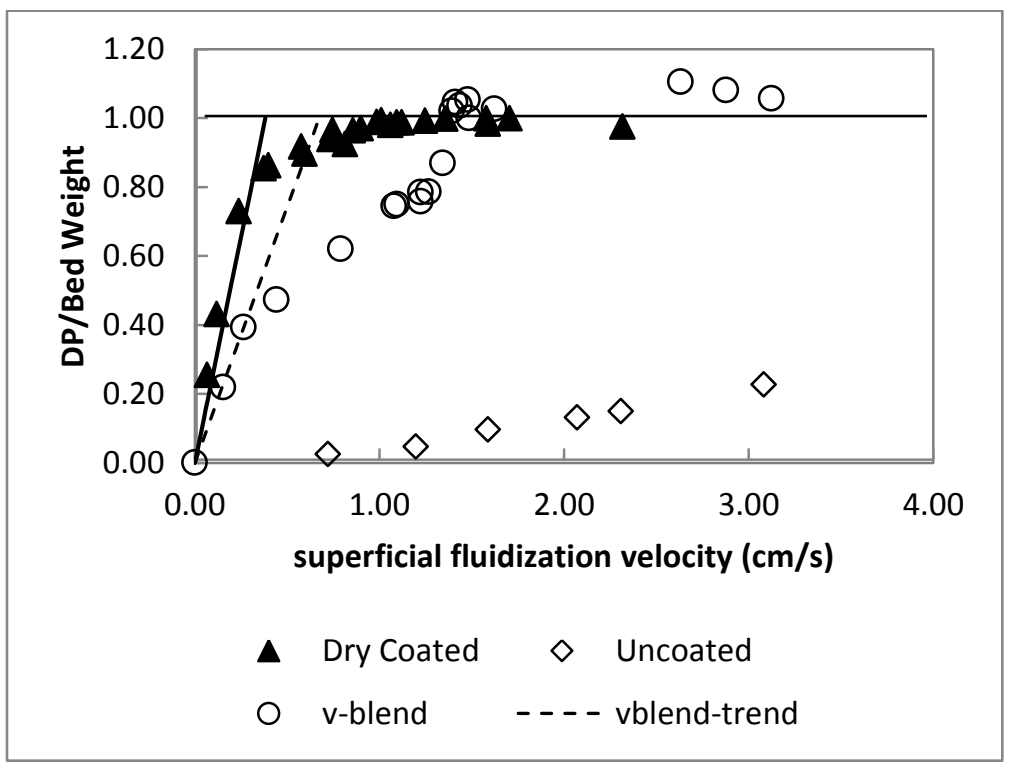

Figure 4: De-fluidization profile of $74 \mu \mathrm{m}$ ibuprofen with and without silica. 


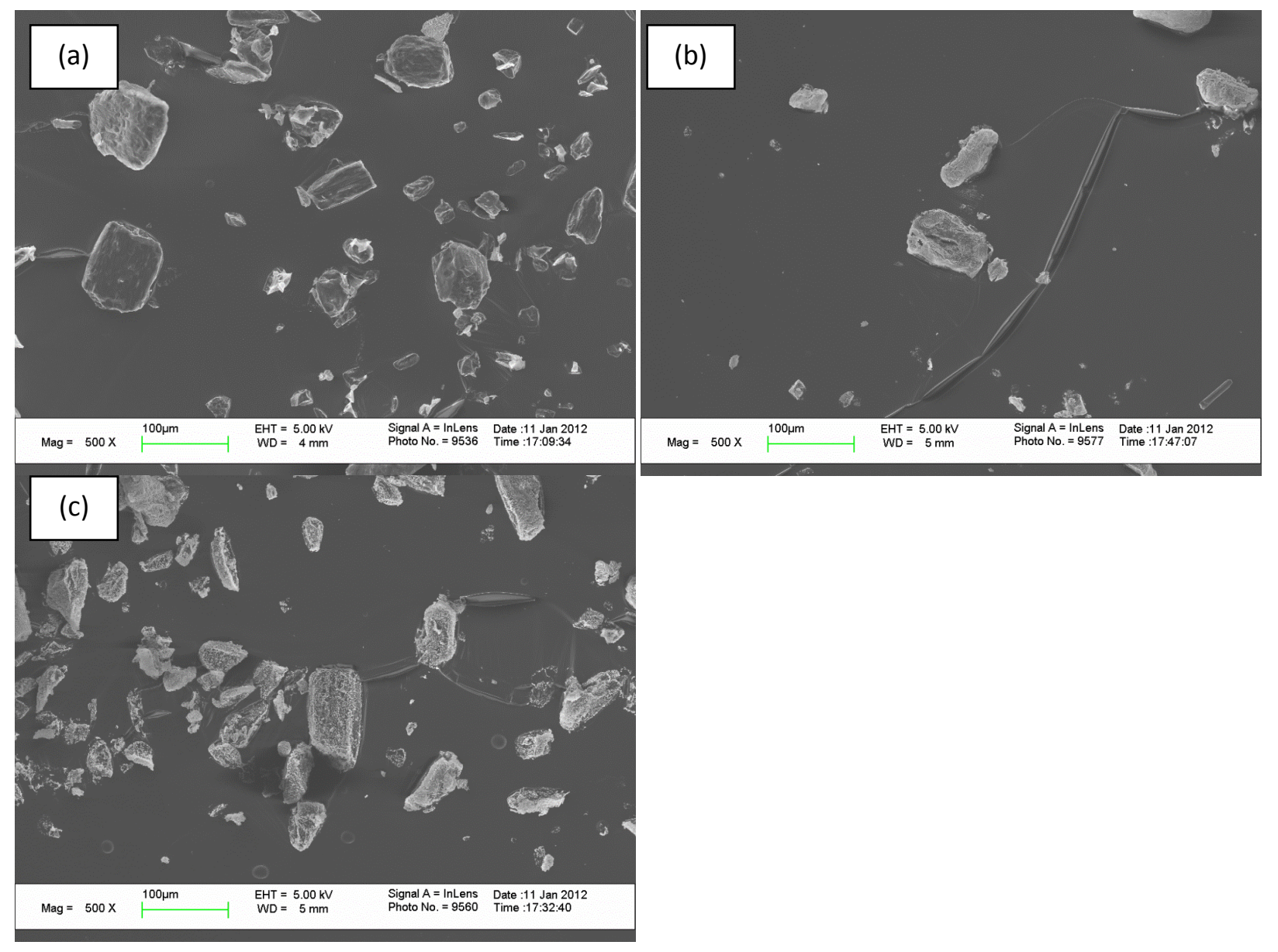

Figure 5: SEM images of milled IBU90 (a) before and after processing with silica in (b) LabRAM dry coating and (c) V-blending.

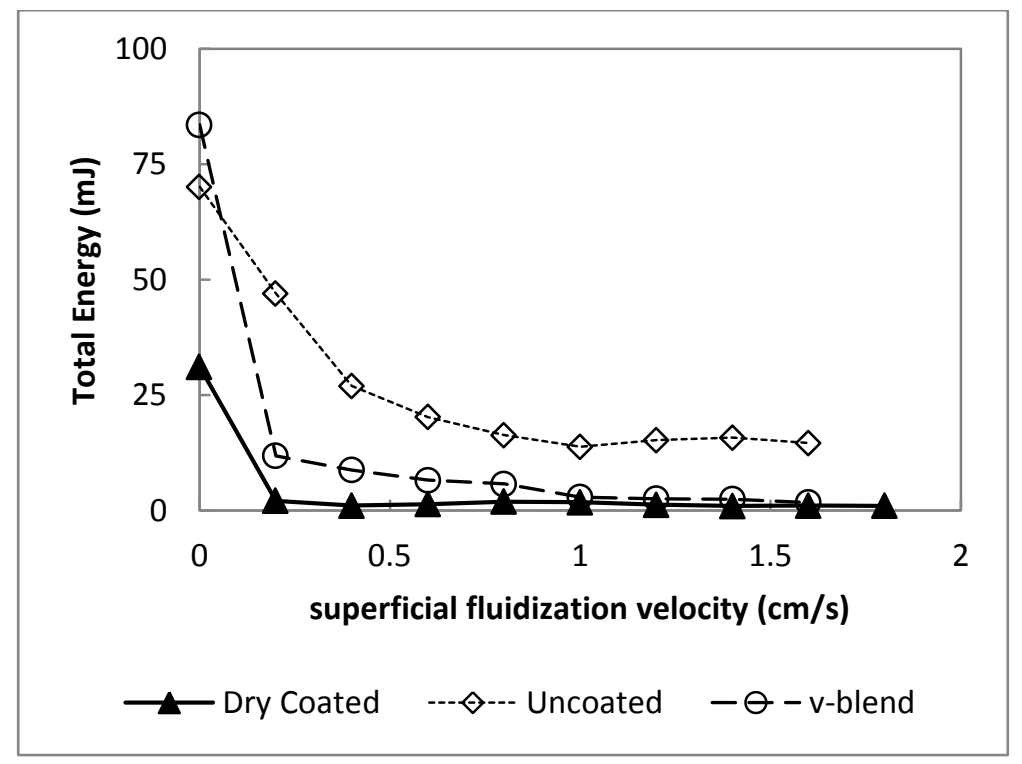

Figure 6: Total energy consumed by the condition blade at various gas velocities for dry coated, uncoated and vblended $41 \mu \mathrm{m}$ powders. 


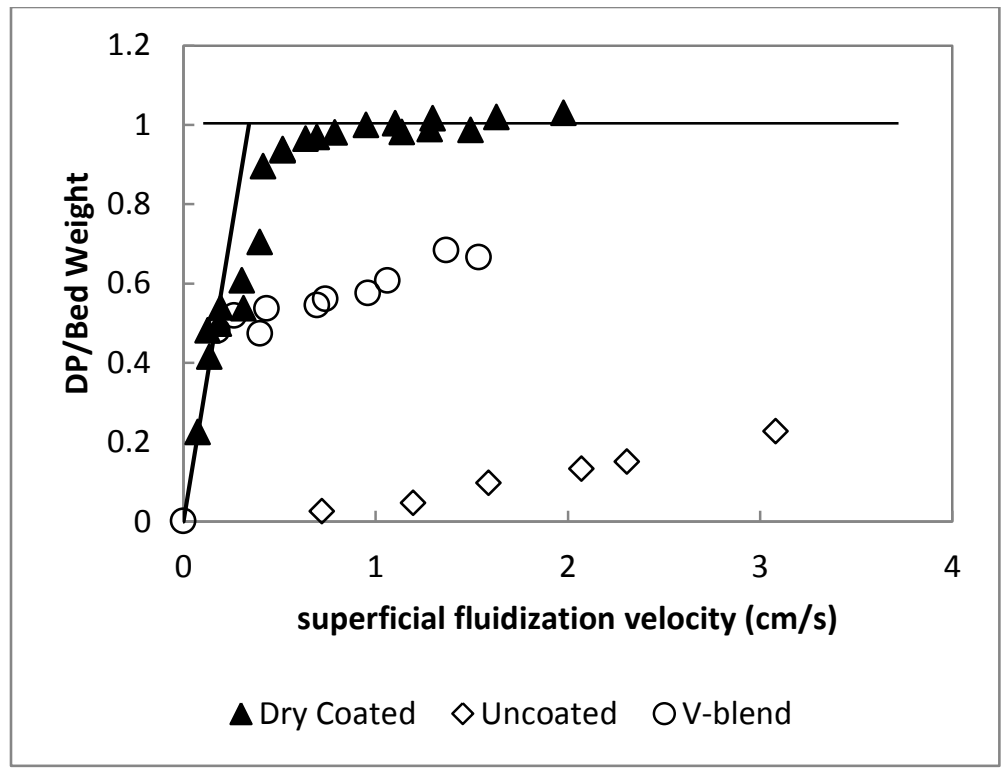

Figure 7: De-fluidization profile of $41 \mu \mathrm{m}$ ibuprofen with and without silica. 


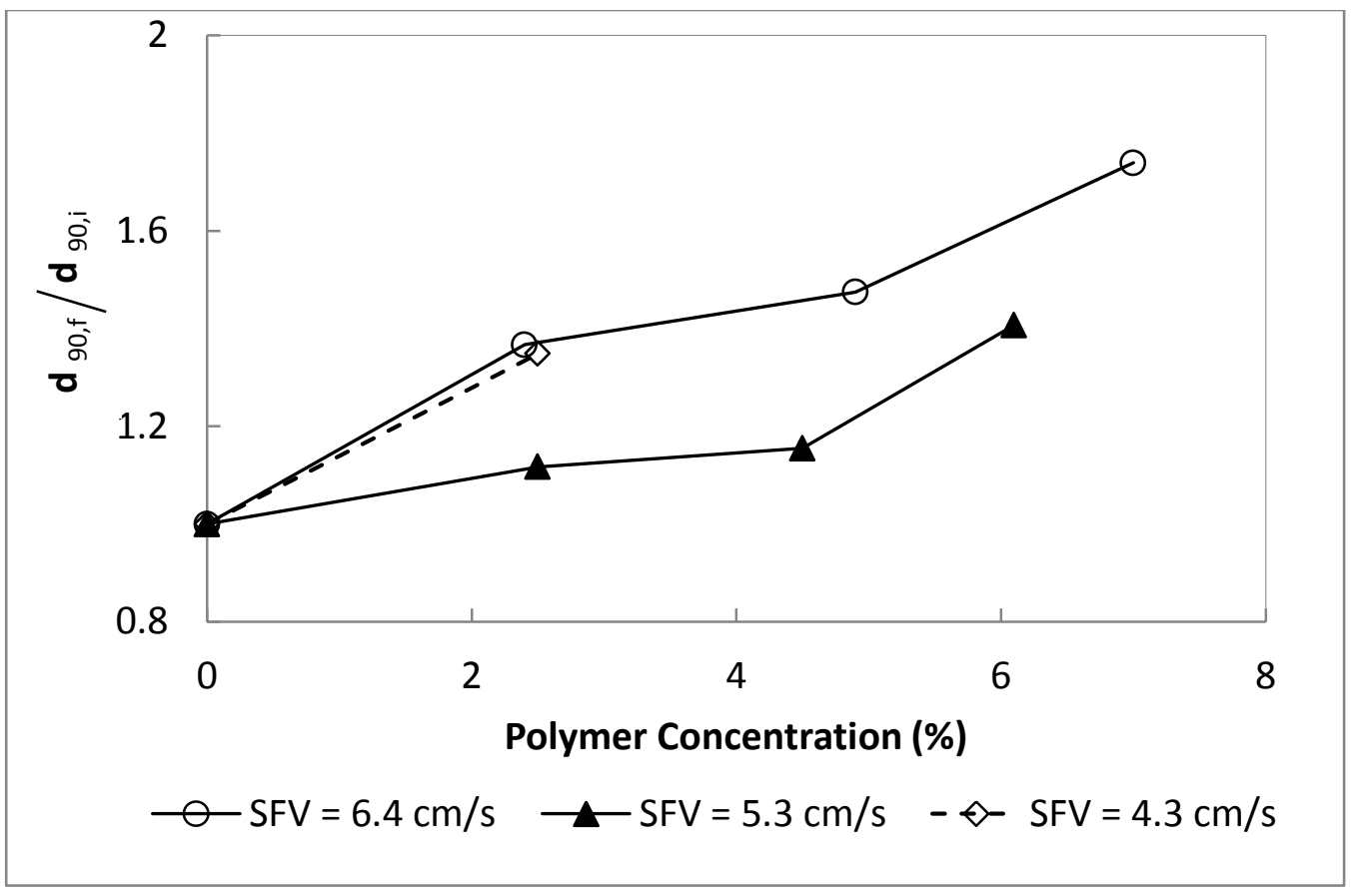

Figure 8: $d_{90}$ ratio of DC-74 ibuprofen powders fluid bed coated with suspension S1 at various superficial fluidization velocities.

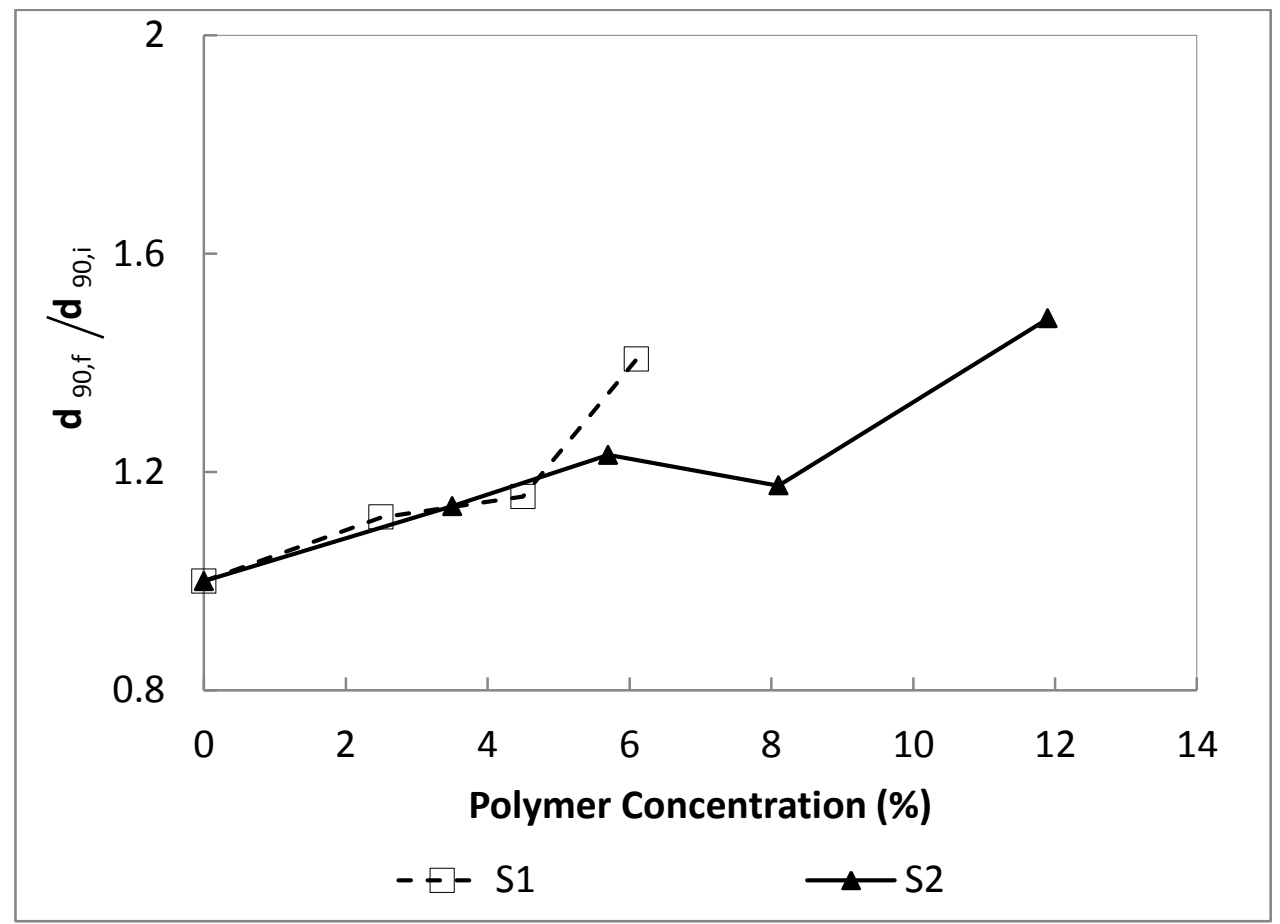

Figure 9: $d_{90}$ ratio of DC-74 ibuprofen powders fluid bed coated with suspension S1 and S2 at a superficial fluidization velocity of $5.3 \mathrm{~cm} / \mathrm{s}$. 

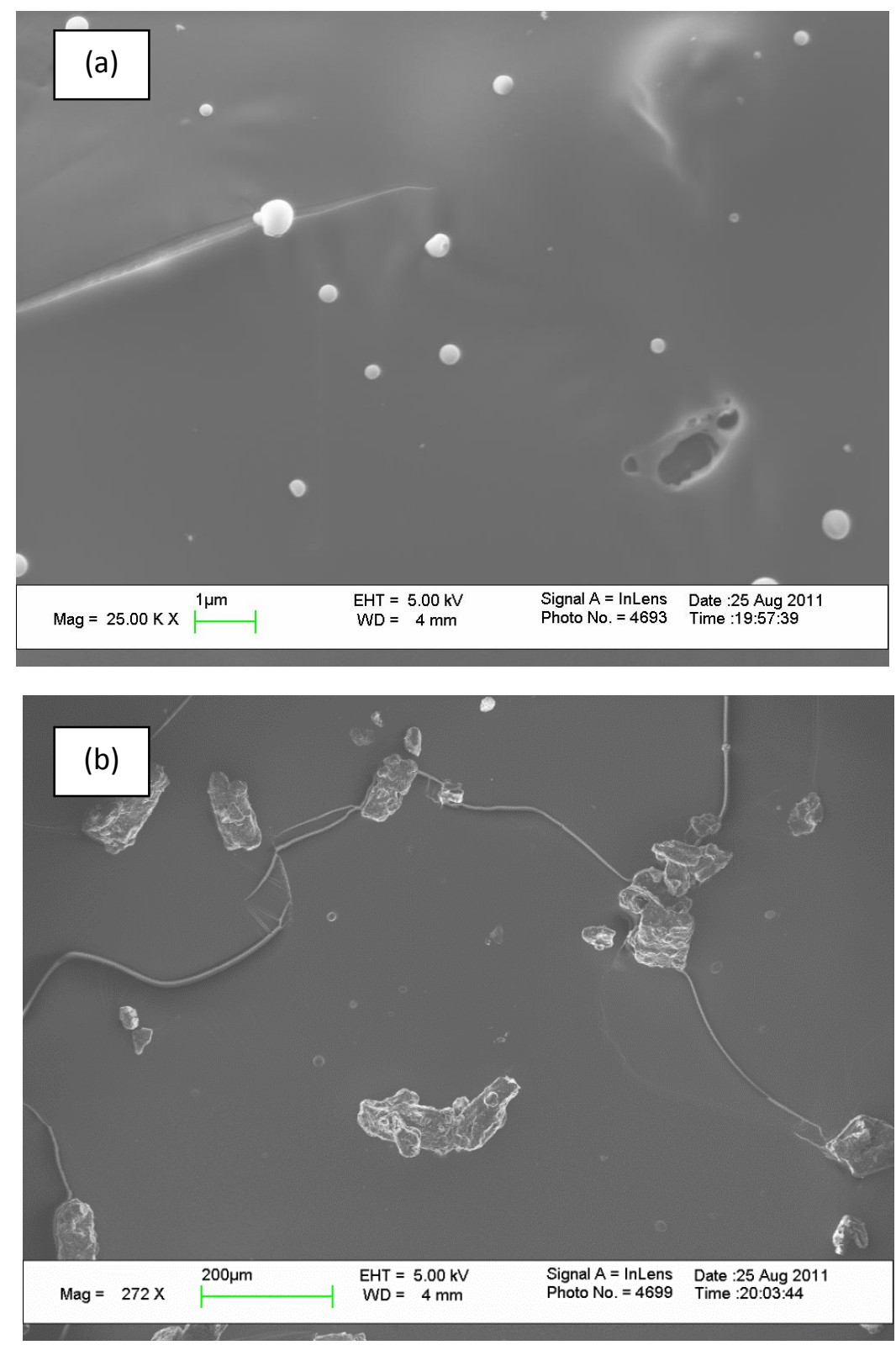

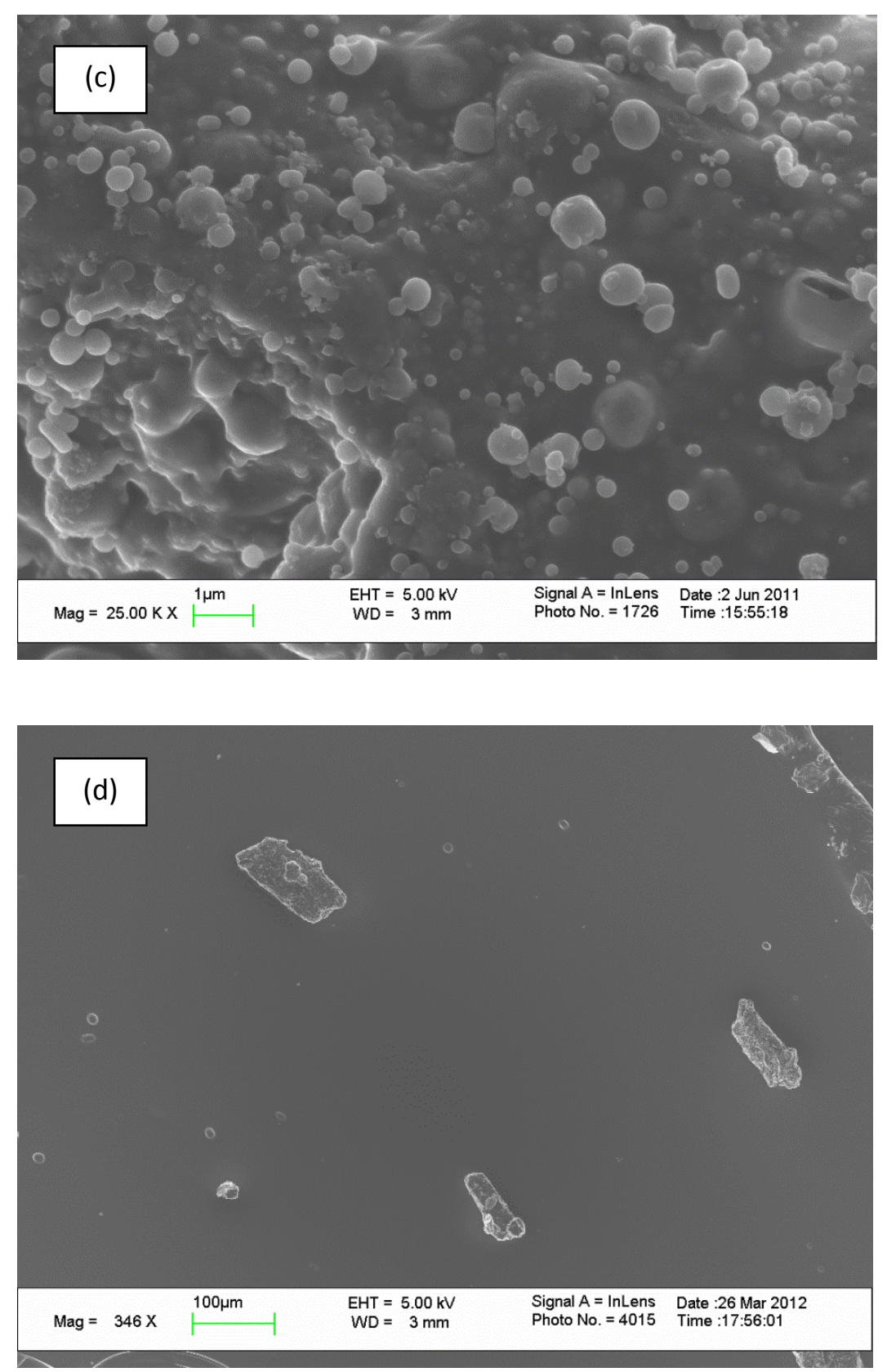

Figure 10: SEM images of the surface of DC-74 ibuprofen after fluidized bed coating (a) with suspension S1, high magnification (without silica), (b) with suspension S1, low magnification (without silica), (c) with suspension S2, high magnification (with silica), and (d) with suspension S2, low magnification (with silica). 


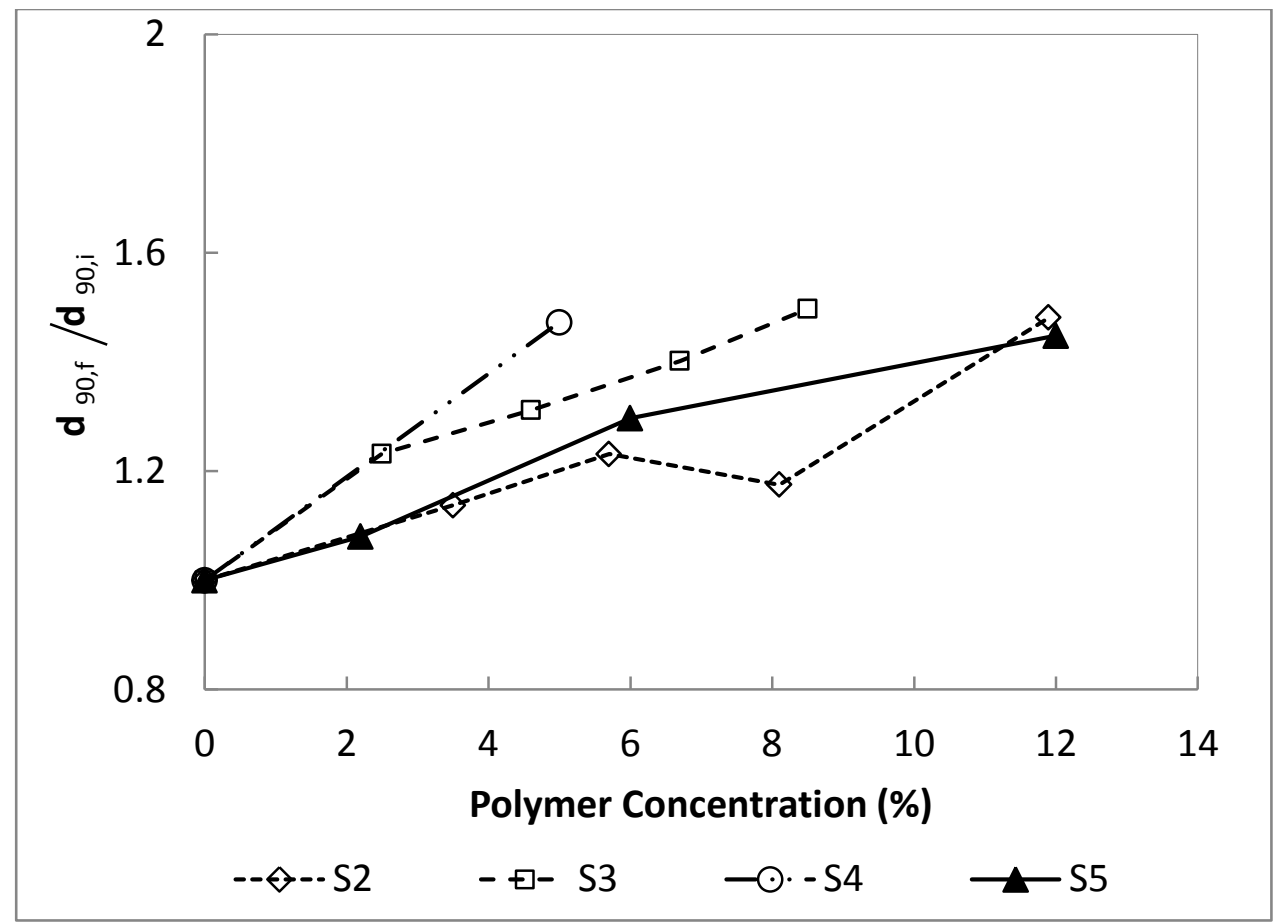

Figure 11: $d_{90}$ ratio of DC-74 ibuprofen powders fluid bed coated with suspension S2, S3, S4 and S5 at a superficial fluidization velocity of $5.3 \mathrm{~cm} / \mathrm{s}$. 

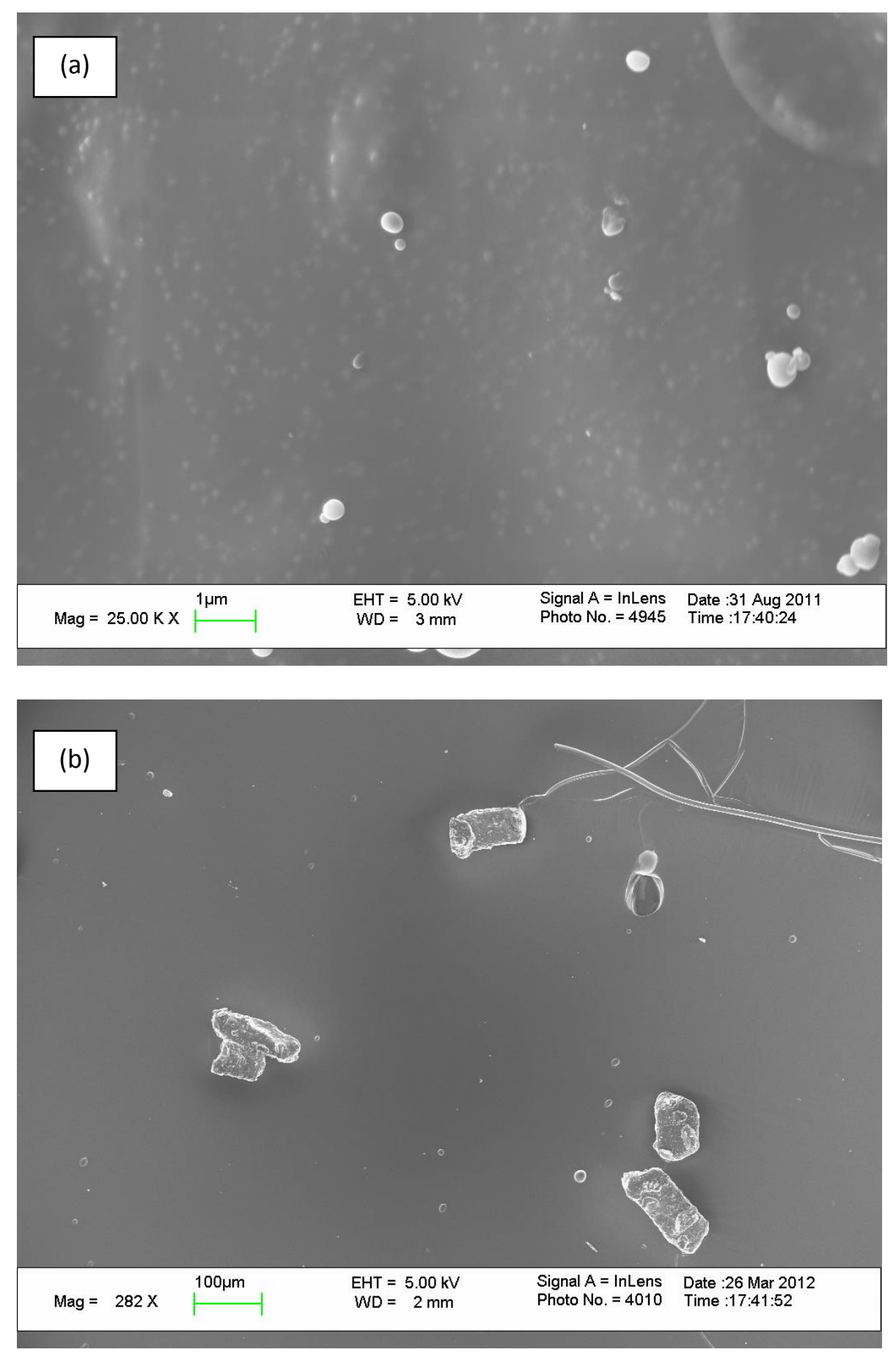

Figure 12: (a) High magnification and (b) low magnification SEM images of DC-74 ibuprofen after fluid bed coating with stabilized silica suspension S5. 

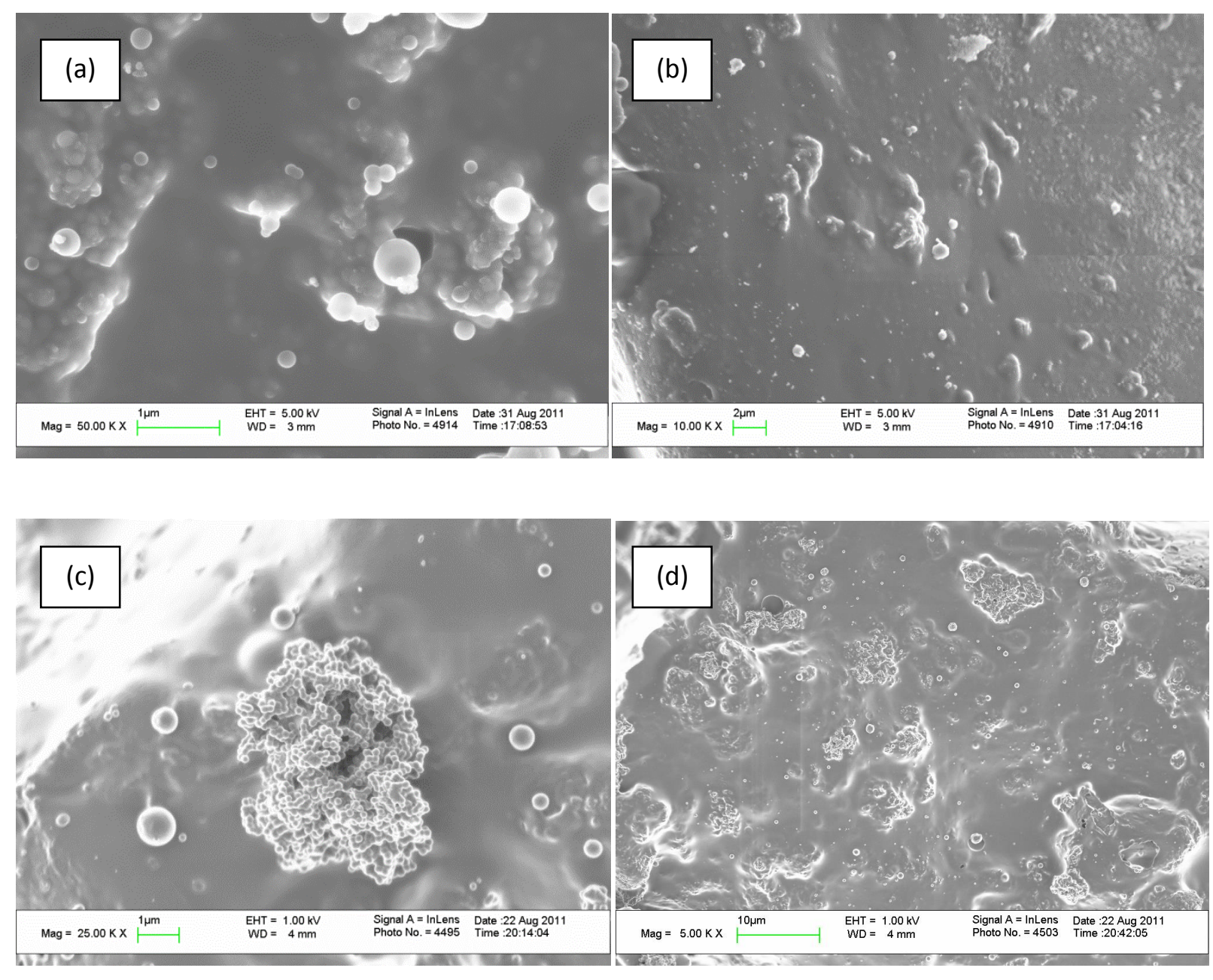

Figure 13: SEM images of the surface of DC-74 ibuprofen after fluid bed coating stabilized silica suspensions (a) S3 zoomed in, (b) S3 zoomed out, (c) S4 zoomed in, (d) S5 zoomed out. 


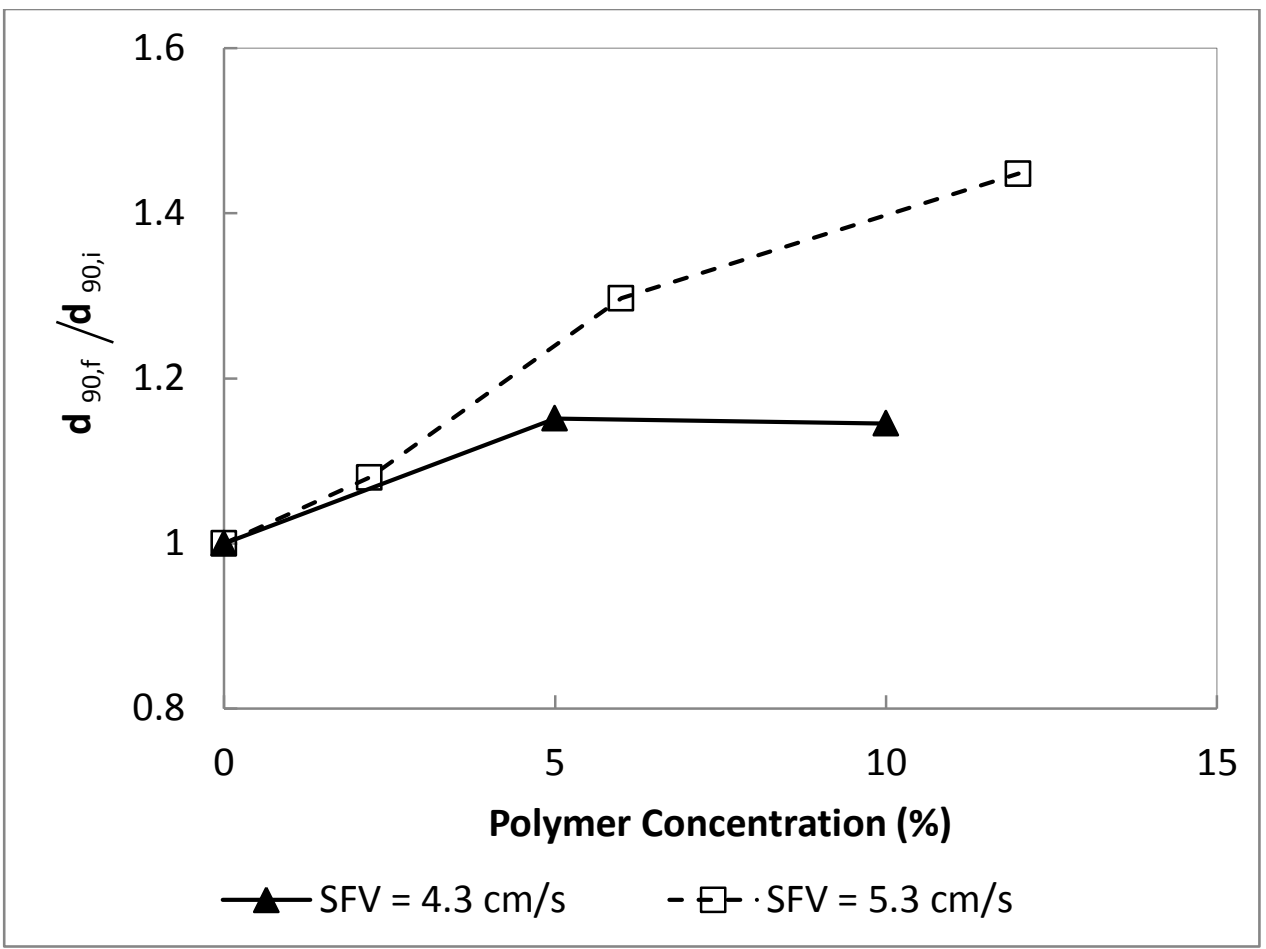

Figure 14: $d_{90}$ ratio of DC-74 ibuprofen fluid bed coated with suspension S5 at superficial gas velocities of 4.3 and $5.3 \mathrm{~cm} / \mathrm{s}$.

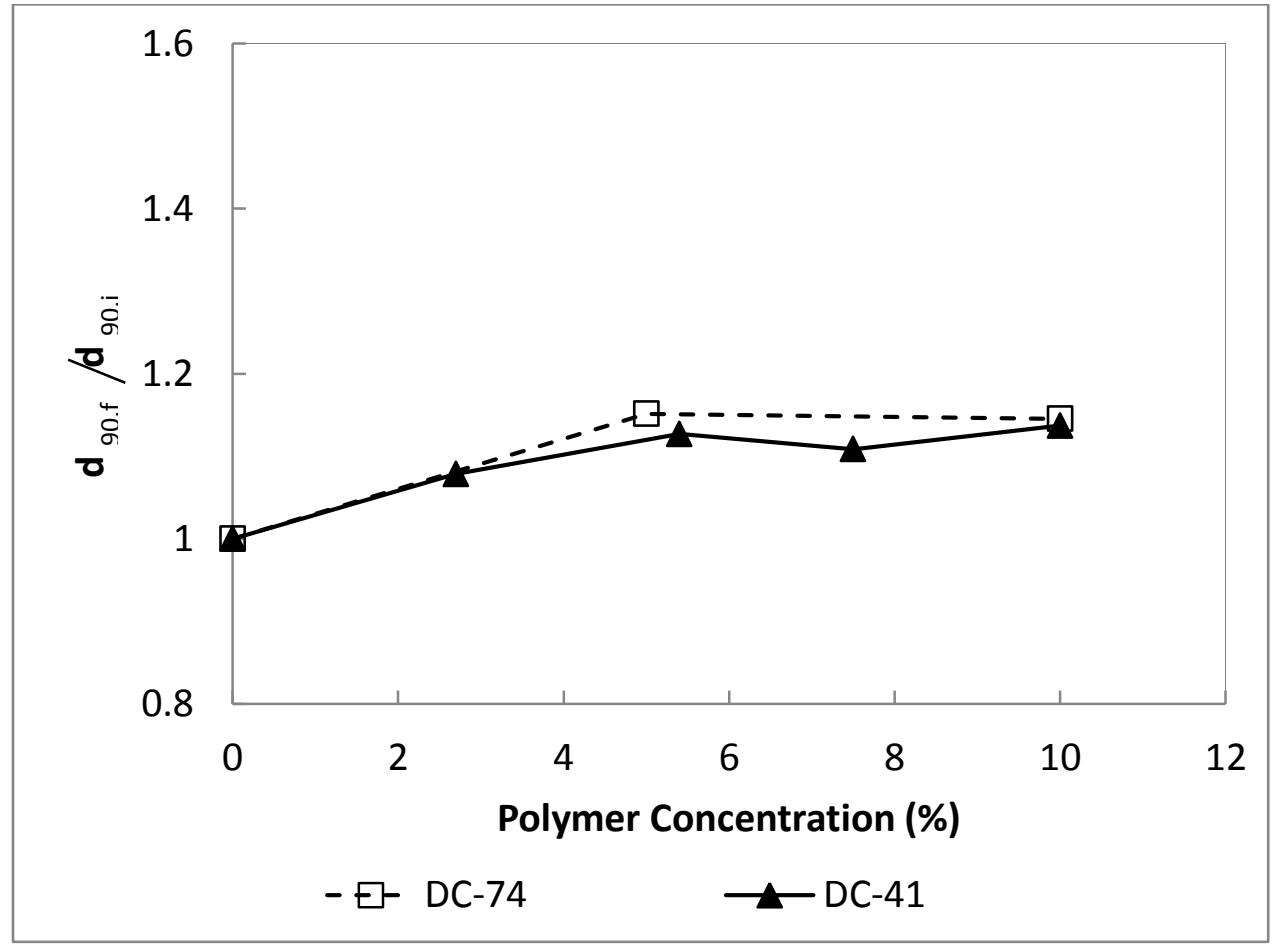

Figure 15: $d_{90}$ ratio of DC-74 and DC-41 fluid bed coated with suspension S5. 

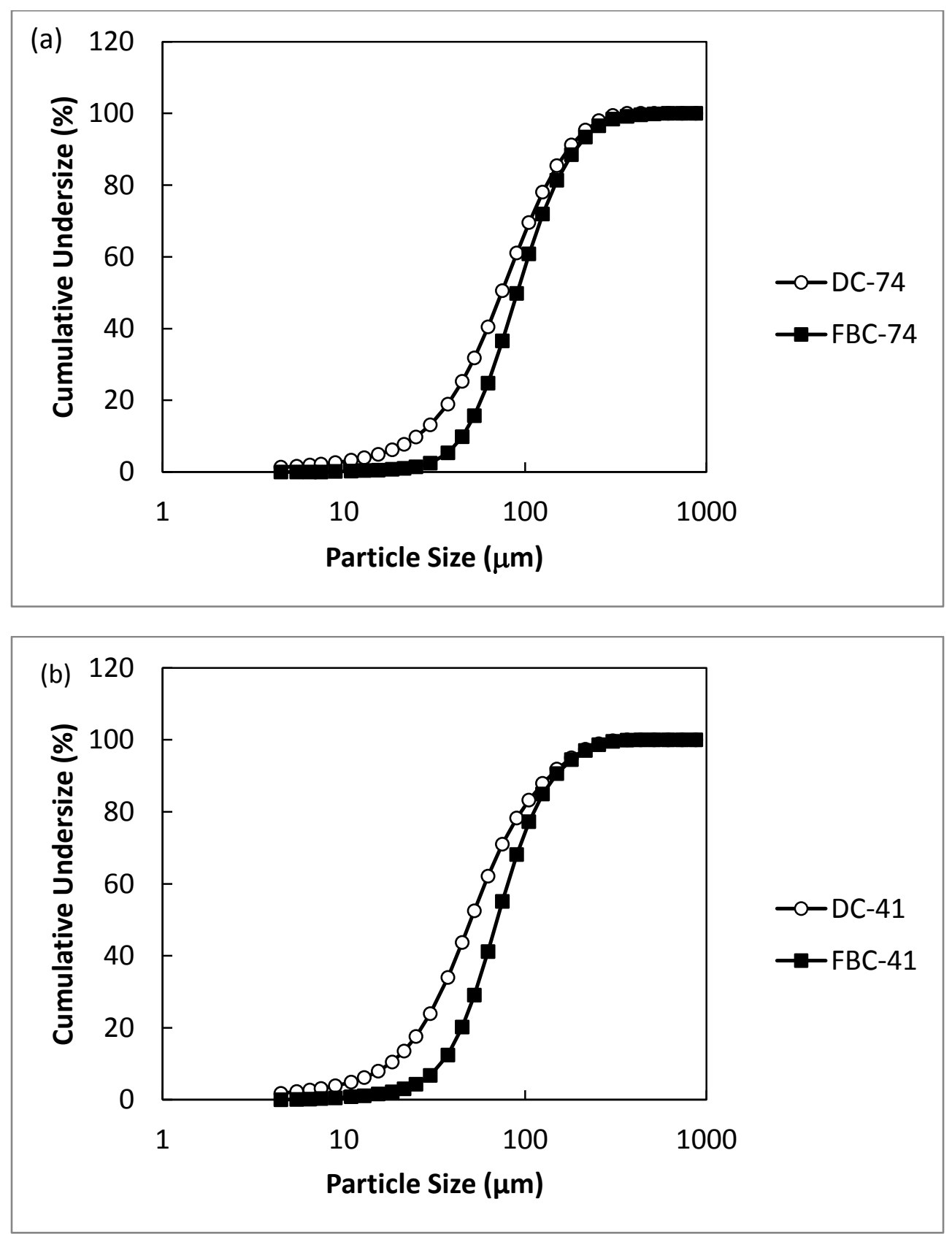

Figure 16: Cumulative volume size distributions of dry coated and fluidized bed coated ibuprofen powders at a $10 \%$ weight gain for (a) DC-74 and (b) DC-41. 

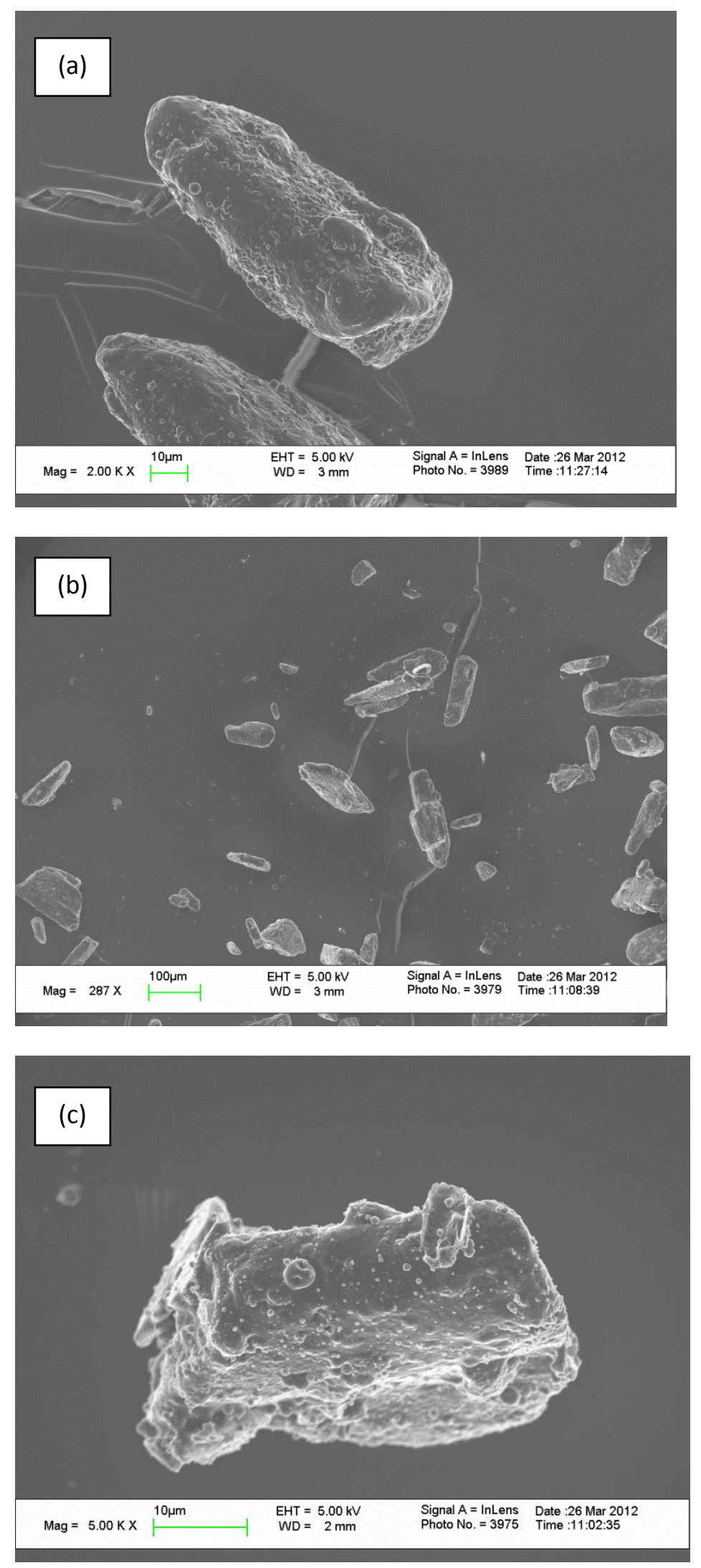


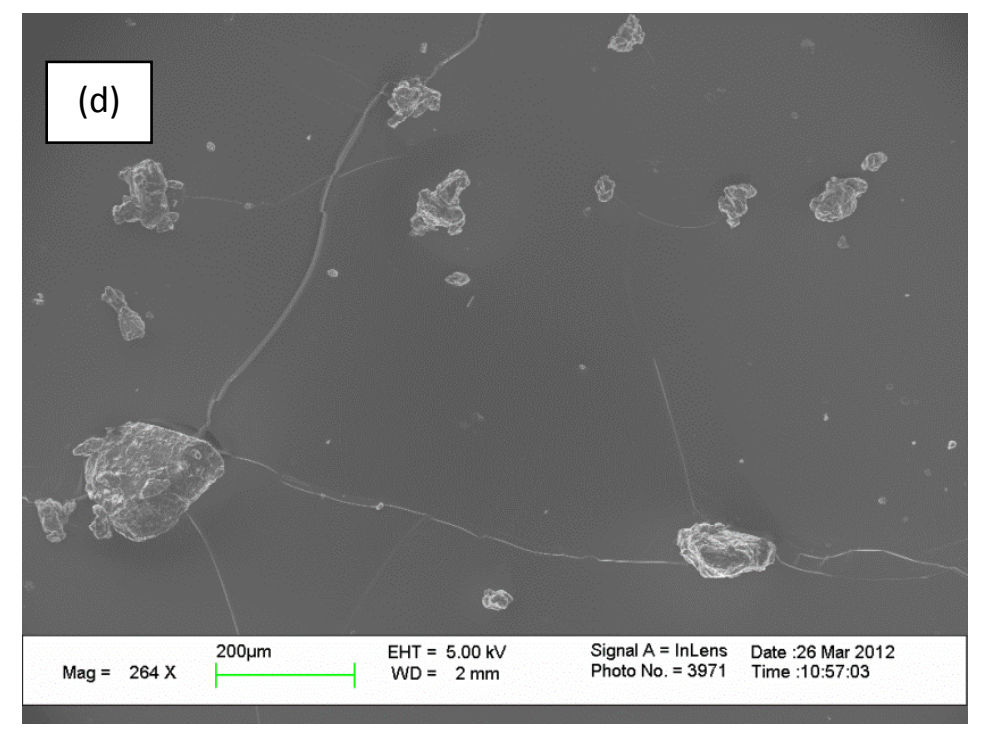

Figure 17: SEM images of fluidized bed coated ibuprofen at a polymer loading of 10\%; DC-74, (a) high, (b) low; and DC-41, (c) high, (d) low. 
Polymer film coating via fluid bed processing of Geldart groups $C$ dry coated ibuprofen powders
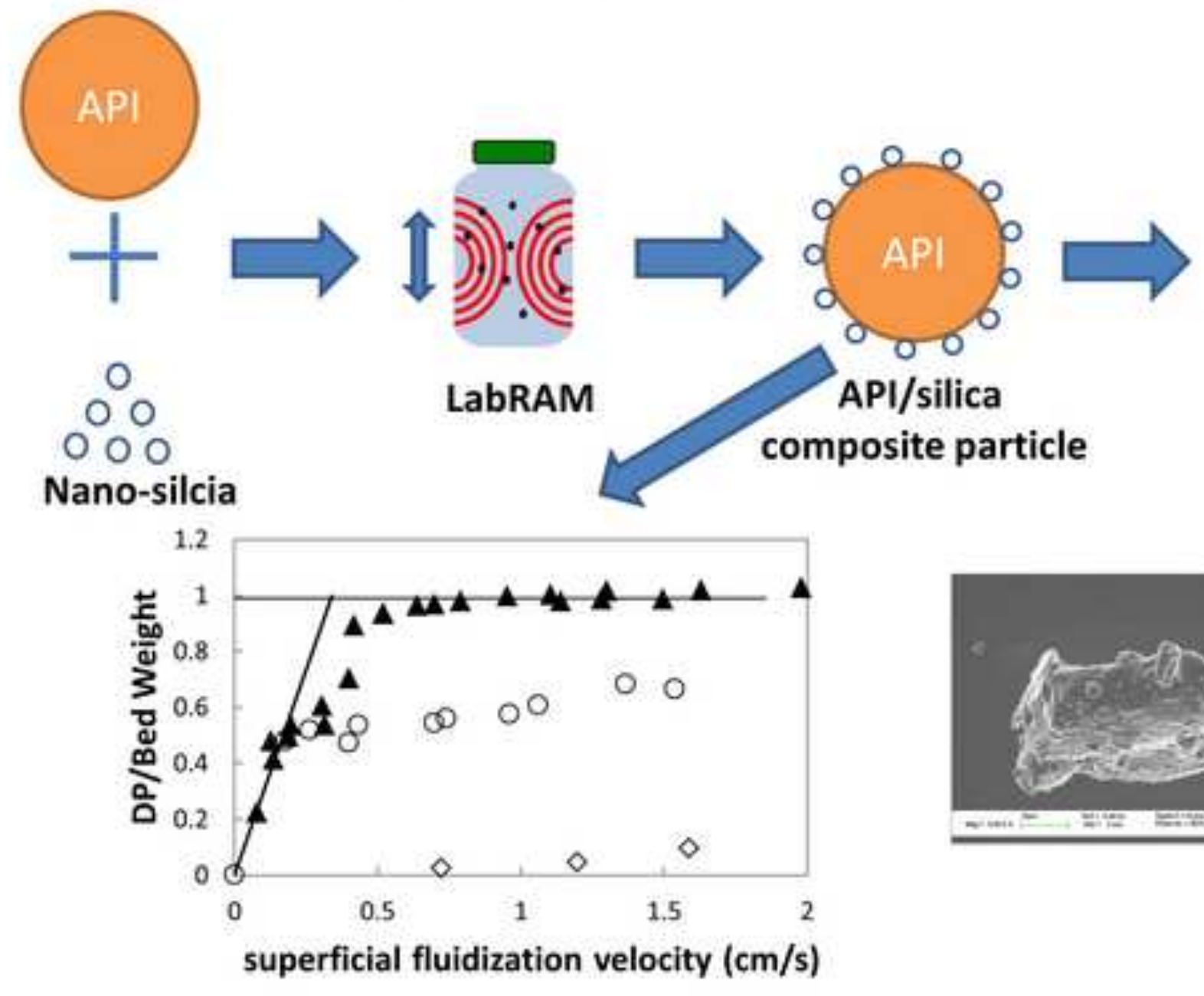

$\Delta$ Dry Coated $\diamond$ Uncoated $\circ \mathrm{V}$-blend

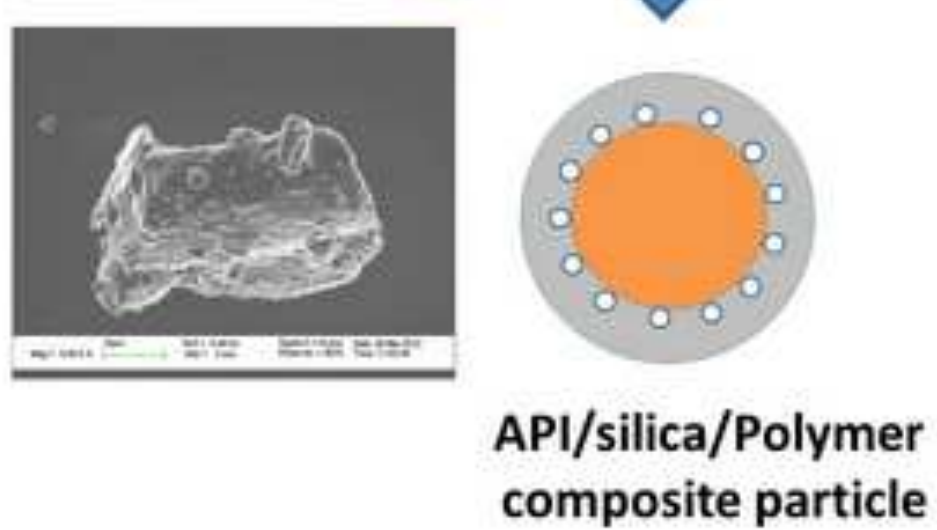

